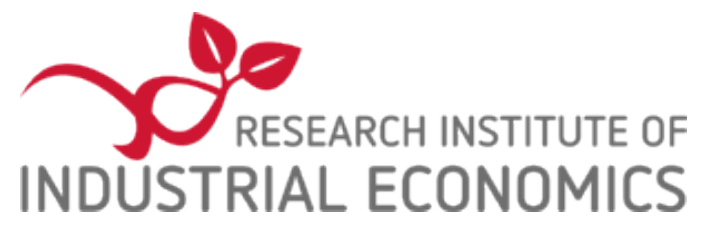

IFN Working Paper No. 1102, 2015

\title{
Entry Regulations, Welfare and Determinants of Market Structure
}

Florin Maican and Matilda Orth 


\title{
Entry Regulations, Welfare and Determinants of Market Structure*
}

\author{
Florin Maican ${ }^{\dagger}$ and Matilda Orth ${ }^{\ddagger}$
}

December 28, 2015

\begin{abstract}
We use a dynamic oligopoly model of entry and exit with store-type differentiation to evaluate how entry regulations affect profitability, market structure and welfare. Based on unique data for all retail food stores in Sweden, we estimate demand, recover variable profits, and estimate entry costs and fixed costs by store type. Counterfactual policy experiments show that welfare increases when competition is enhanced by lower entry costs. Protecting small stores by imposing licensing fees on large stores is not welfare enhancing. This study sheds light on the long-run implications of entry regulations for the welfare of differentiated product industries with endogenous entry and exit.
\end{abstract}

Keywords: Imperfect competition; product differentiation; retail markets; entry; exit; sunk costs; welfare.

JEL Classification: L11, L13, L81.

\footnotetext{
${ }^{*}$ We would like to thank the editor and two anonymous referees for excellent comments and suggestions. Furthermore, we thank John Asker, Emek Basker, Christoph Bauner, Gregory Crawford, Uli Doraszelski, Paul Grieco, Igal Hendel, Ariel Pakes, Amil Petrin, Mark Roberts, Junichi Suzuki, Yuya Takahashi, Otto Toivanen, Frank Verboven and seminar participants at the Swedish National Conference in Economics (Uppsala), the thirteenth CEPR/JIE Conference on Applied IO, EEA-ESEM, EARIE, and IIOC for their valuable comments. Special thanks to DELFI Marknadspartner, the Swedish Consumer Agency, Värderingsdata and the Swedish National Organization of Pensioners (PRO) for providing the data. Financial support from the Swedish Retail and Wholesale Development Council, Torsten Söderbergs Stiftelse, and the Swedish Competition Authority is gratefully acknowledged.

${ }^{\dagger}$ Research Institute of Industrial Economics (IFN) and University of Gothenburg, Box 640, SE-405 30, Göteborg, Sweden, Phone +46-31-786 4866, Fax: +46-31-786 4154, E-mail: florin.maican@ifn.se; florin.maican@economics.gu.se

${ }^{\ddagger}$ Research Institute of Industrial Economics (IFN), Box 55665, SE-102 15, Stockholm, Sweden, Phone +46-8-665 4531, Fax: +46-8-665 4599, E-mail: matilda.orth@ifn.se
} 


\section{Introduction}

The effect of regulation on market structure and welfare is a topic of great concern for both economists and policymakers. Entry regulations in the retail food industry, which are more restrictive in Europe than in the US, are one such example. ${ }^{1}$ The welfare effects of entry regulations are theoretically ambiguous and depend on the substitutability among different types of stores. Promoting entry leads to more intense competition, which can in turn increase consumer welfare through lower prices, higher quality and variety. Social welfare, however, can decrease because more stores have to pay sunk costs and fixed costs and because entrants take market share from incumbents. The overall welfare effect of entry regulations is thus an empirical question, which we aim to address in this paper. ${ }^{2}$

We present a dynamic oligopoly model of entry and exit with product differentiation that incorporates a static model of price setting and recovers both the entry costs of potential entrants and the fixed costs of incumbents in local markets under different degrees of regulation. This paper quantifies the impact of entry regulations on welfare, long-run profits and the evolution of market structure using a unique combination of data on store characteristics for all retail food stores in Sweden during the 2001-2008 period and data on store-level prices and regional and regulatory information. Based on the structural estimates, we re-solve the dynamic oligopoly model under different entry regulation regimes and quantify their impact on social welfare.

Entry regulations are important in industries characterized by local competition, which includes most retail and services industries. Regulations are considered an entry barrier that influence the decision to enter. Each store seeking entry into retail markets is typically required to file a formal application with the local government. Local governments approve or reject applications after evaluating the potential impact of the store's entry on aspects like prices, market shares and concentration. Land use regulation that controls entry influences store costs because stores must have a physical location to operate, and buildings constitute a major portion of stores' capital expenses. Entry regulations that determine whether a store may be built as well as the design of the building clearly affect store costs. By influencing store costs, entry regulations can have anti-competitive effects (Suzuki, 2013; Nishida, 2014). Municipal administrative processes and politics also contribute

\footnotetext{
${ }^{1}$ See, e.g., European Parliament (2008); European Competition Network (2011); European Commission (2012).

${ }^{2}$ We focus on the economic cost of entry regulations that protect small business profits and suppress competition. Other motivations for entry regulations include preventing environmental damage and traffic. We do not consider these aspects in our analysis.
} 
to regulatory costs. Thus, the impact of entry regulations on costs and thus on the intensity of competition is clear.

Our dynamic model builds on Pakes, Ostrovsky and Berry (2007) [POB] and explicitly incorporates demand, local markets, differentiation of store type, strategic interactions between stores, and the presence of regional entry regulations. The welfare consequences of various entry regulations depend on the substitutability among different types of stores (e.g., small stores and large stores); thus it is important to model demand using heterogeneity in store size. Because product differentiation and simultaneous entry and exit characterize nearly all retail markets, this implies that we must model heterogeneous stores and the dynamics of market structure over time.

This paper makes several contributions to the literature. First, to the best of our knowledge, no study has combined detailed information on the total population of stores with data on food prices to evaluate the consequences of regulations on welfare in the retail industry. ${ }^{3}$ Second, our study contributes to the scarce literature that combines a demand model of differentiated products with a dynamic game of entry and exit (e.g., Gowrisankaran and Town, 1997; Benkard, 2004; and Sweeting, 2013). We use the model to evaluate how entry regulations in retail affect long-run market outcomes. Our framework captures market adjustments that can be captured only by using a dynamic model and demand with differentiated products. We evaluate the impact of entry costs on substitutability among store types and how changes in substitutability affect welfare. Third, our policy experiments contribute to the understanding of the pros and cons of different entry regulation regimes and their impact on market structure dynamics and welfare. ${ }^{4}$ Food consumption represents a large share of private consumption, and the welfare implications of various policies are likely to be substantial. ${ }^{5}$

There are a number of characteristics of the Swedish retail food market that make the application of our theoretical model particularly appropriate. Swedish food retailers operate well-defined store types, are highly independent and determine their own prices. Focusing on store types is appropriate for Sweden because, to a large extent, independent store owners operate the stores, thus

\footnotetext{
${ }^{3}$ This combination of store characteristics and prices is rare, for example, because of the complexity of measuring retail food prices; it allows us to carefully evaluate the effect of regulations and the dynamics of the local market industry. Beresteanu et al. (2010) combine store characteristics for a panel and prices for a single cross-section of data in their study of Walmart. In contrast to their study, we observe panel data on prices and focus on the role of entry regulations.

${ }^{4}$ For contributions considering a static entry game with demand, see Berry and Waldfogel (1999), Gowrisankaran and Krainer (2011), and Maruyama (2011). For recent work on entry regulations, see, e.g., Suzuki (2013), Turner et al. (2014) and the survey by Pozzi and Schivardi (2015).

${ }^{5}$ Total annual food expenditures in the US exceed USD 1,100 billion; the average household purchases groceries every week and spends as much as an hour per trip. Food consumption represents approximately 10 percent of private consumption in the US and up to 20 percent of private consumption in most European countries.
} 
reducing the influence of national firms, and all stores (not only large stores) are affected by entry regulations. Store entry and exit are the main determinants of the market structure. In addition, the trend toward larger but fewer stores has not changed over the last few decades in most OECD countries. ${ }^{6}$ Because of this a dynamic approach is crucial in retail (Figure 1). Store-type differentiation is essential, as large stores represent only 20 percent of the total number of stores but over 60 percent of aggregate sales and sales space (Table 1).

More generally, our paper is related to the literature on dynamic oligopoly models based on Ericson and Pakes (1995) (Aguirregabiria and Mira, 2007; Bajari et al., 2007; Pakes et al., 2007; Pesendorfer and Schmidt-Dengler, 2008). Our study relates to the scarce but growing empirical literature that uses a dynamic oligopoly framework to evaluate the importance of dynamics for welfare (e.g., Gowrisankaran and Town, 1997; Benkard, 2004; Ryan, 2012; Sweeting, 2013; Collard-Wexler, 2013; Fowlie et al., 2014). ${ }^{7}$ In addition to POB, our paper is most closely related to Dunne et al. (2013), who model identical firms using data on dentists and chiropractors. Fan and Xiao (2015) analyze the deregulation of the US telephone market and allow for option values of waiting in entry decisions. Furthermore, Suzuki (2013) models and empirically evaluates the impact of land-use regulations on the entry and exit of hotel chains.

Our analysis proceeds in four steps. First, we estimate a discrete choice model of static demand to analyze how consumers choose stores. Second, we use the demand estimates to calculate variable profits in all possible states using the Nash-Bertrand equilibrium assumption together with a marginal cost function. Third, using a dynamic model, we estimate the parameters of entry cost and fixed cost distributions for small and large stores and local markets that vary with respect to the stringency of entry regulations. The structural parameters of the distributions of entry costs and fixed costs are estimated by matching the observed entry and exit rates in the data to those predicted by the model. Fourth, we use the structural estimates to compute equilibrium outcomes and welfare effects under a number of alternative entry regulation regimes that are frequently debated among policymakers in the US and Europe.

\footnotetext{
${ }^{6}$ The evaluation of entry costs for different store types and the factors affecting these costs provide crucial information in markets in which the average travel distance for purchasing food increases. In Sweden, the average travel distance for purchasing food was approximately 9.83 kilometers during the 1995-2002 period (The Swedish Institute of Transport and Communication).

${ }^{7}$ Berry and Reiss (2007) and Ackerberg et al. (2007) survey the literature on static and dynamic entry games. Doraszelski and Pakes (2007) survey the literature on applied dynamic analysis in IO. Our study also relates to a growing body of literature on retail: chain expansion where exit is extremely rare (e.g., Toivanen and Waterson, 2011; Beresteanu et al., 2010; Holmes, 2011; Basker et al., 2012; Arcidiacono et al., 2013); static models that account for store location (e.g., Seim, 2006; Jia, 2008; Orth, 2011; Ellickson et al., 2013; Nishida, 2014); dynamic models of store format repositioning or multiple stores (e.g., Maican, 2010; Aquirregabiria and Vicentini, 2015; Igami and Yang, 2015).
} 
The results show differences in own- and cross-price elasticities such that small stores gain more market share than large stores when the price of the rival store type increases. There is asymmetric competition across store types. An additional large store decreases static variable profits by 4 percent for small stores and by 10 percent for large stores. Under the current regulation, entry costs for large stores are lower and average welfare is higher in local markets with liberal rather than restrictive regulation. The discounted producer surplus is on average about four times larger than the discounted consumer surplus.

We examine several counterfactual policy experiments. First, protecting small stores either by imposing a licensing fee or higher entry costs for large stores is not welfare improving, in particular in markets that already face restrictive regulation. Second, promoting competition by lowering entry costs for either small or large entrants is welfare enhancing. While the increase in average discounted consumer surplus is similar, average discounted producer surplus decreases slightly more when the entry of large stores is promoted rather than small stores. Welfare improvements are primarily driven by medium and large markets and are larger in liberal than in restrictive markets. Therefore, to accurately evaluate the effect of alternative entry regulation policies on welfare, it is important to consider that changes in the costs faced by one store type have implications for the endogenous entry, exit, and long-run profits of the rival store type.

The next section presents the data and market. Section 3 presents the dynamic model. Section 4 discusses the empirical implementation of the model, whereas Section 5 presents the empirical results. Section 6 reports the results of several counterfactual exercises that highlight the importance of turnover, long-run profitability and trade-offs between different store types for welfare, and Section 7 discusses robustness. Finally, Section 8 concludes the paper. In several instances, we refer to an online appendix containing various analyses that are not discussed in detail in the paper.

\section{Data and characteristics of the Swedish retail food market}

Many retail food markets in OECD countries consist of firms that operate uniformly designed store types. In Sweden, the food market consists of stores that, to a large extent, operate as independent or franchise units. Importantly, stores have independent pricing strategies. This is in contrast to national pricing, which exists, for example, in the UK. Centralized decision making - and thus the concern regarding national strategies - in the Swedish retail food market is thus less pronounced 
than in many other countries. Firms primarily act as wholesale providers, and the degree of centralization varies somewhat across firms. One firm, ICA, consists of independently owned stores that traditionally collaborate on wholesale provision and logistics. Two firms, Axfood and Bergendahls, each have a combination of franchises and centrally owned stores, the latter of which are primarily located in the south and southwest of Sweden. Coop consists of centralized cooperatives, and decisions are made at the national or local level. In 2011, approximately 90 percent of all stores were connected to one of four firms: ICA (49 percent), Coop (22 percent), Axfood (15 percent), and Bergendahls (7 percent). Various independent owners comprise the remaining 7 percent market share. International firms with hard discount formats entered the Swedish market in 2002 (Netto) and 2003 (Lidl).

Data. Three different data sets that cover stores, demographics, and prices are incorporated in our empirical application. The first and primary data set includes all retail food stores in the Swedish market during the 2001-2008 period and is collected by Delfi Marknadsparter AB (DELFI). A unit of observation is a store based on its geographical location, i.e., its physical address. We have information on each store's geographic location (geo-coordinates), store type, firm affiliation, sales, sales space (in square meters), wholesaler and the location (geo-coordinates). The store type classification (12 different) depends on size, location, product assortment, and so forth. Store types are similar for stores that are affiliated with different firms, and we jointly analyze several store types in the dynamic analysis. We define the five largest types (hypermarkets, department stores, large supermarkets, large grocery stores, and others) as "large" and four other types (small supermarkets, small grocery stores, convenience stores, and mini-markets) as "small." 8 We believe that these types are representative of small and large stores in the Swedish retail food market. Due to the complexity of defining the output and the variety of product assortments across stores, as is common in studies on the retail food market, we do not have information on the quantity sold for each product.

The second data set contains demographic information from Statistics Sweden (SCB), i.e., population, population density, average income, distribution of income across age groups, and political preferences. The third data set is collected by the Swedish National Organization of Pensioners (PRO) and contains annual price information for approximately 30 products in approximately 1,000 stores during the 2003-2008 period. The data set is rich and covers stores of different sizes, formats and firms across all counties in Sweden. The surveyed products cover a wide range of frequently

\footnotetext{
${ }^{8}$ Gas stations, seasonal stores, and stores under construction are excluded from the analysis. Stores classified as "other" stores are large and located outside cities.
} 
purchased items of well-defined brands and pack sizes. ${ }^{9}$ Because the empirical implementation of our model relies on all stores, we define a product basket for which we construct a price index by store type, firm, local market and year. In the empirical application, we consider a basket that contains 11 products. Online Appendix B provides details regarding the components of the product basket and descriptive statistics of the price. Section 7 and online Appendix G discuss the estimation results using separate product baskets for small and large stores.

Local markets. Food products fulfill daily needs and are often relatively perishable. Thus, stores are generally located near consumers; the travel distances are relatively short (unless prices are sufficiently low), and proximity to home or work is therefore a key concern for consumers. ${ }^{10}$ The size of the local market of each store depends on its type. Large stores attract consumers from a wider area than do small stores, but the size of the local market also depends on the distance between stores. We assume that retail markets are isolated geographic units, in which stores in one market only competitively interact with other stores in the same local market. The 21 counties in Sweden are clearly too large to be considered local markets for our purposes, while the 1,534 postal areas are likely too small, especially for large stores. Two intermediate choices are the 88 local labor markets or the 290 municipalities. Local labor markets take into account commuting patterns, which are important for the largest stores, such as hypermarkets and department stores, while municipalities appear more suitable for large supermarkets. As discussed below, local government decisions regarding new entrants are made at the municipal level. We therefore use municipalities as local markets.

Entry, exit and market shares. As we have annual data on all Swedish retail stores based on address, we observe the physical entry and exit of stores. We define an entrant in year $t$ as a store that operates in year $t$ but not in $t-1$. We define an exit in year $t$ as a store that operates in year $t-1$ but not in $t$. The variables $e_{m t}$ and $x_{m t}$ measure the number of entrants and exits in market $m$ in year $t$. The total number of stores in the beginning of period $t+1, n_{m t+1}^{\prime}$, is given by $n_{m t+1}^{\prime}=n_{m t}+e_{m t}-x_{m t}$, where $n_{m t}$ is the number of incumbent stores in period $t$. We only consider physical entry and exit as these are the relevant considerations for estimating sunk and fixed costs. Thus, we do not include stores that change owners but continue to operate at the same address.

To construct market share, we use store sales and the price of a large product basket to derive

\footnotetext{
${ }^{9} \mathrm{PRO}$ is divided into a number of geographic districts, approximately corresponding to the 21 counties, which are each responsible for the survey in their geographic area. See Asplund and Friberg (2002) for previous work using the same data source. Based on the names and addresses of the stores in DELFI, we identify the stores that are included in the PRO survey.

${ }^{10}$ The importance of these factors is confirmed by discussions with representatives from ICA, Coop, and Bergendahls.
} 
the quantity of product baskets a store sells in year $t$. Market share is defined as the quantity of product baskets sold divided by the total quantity in each local market and year (Section 4.1). ${ }^{11}$

Entry regulation. The majority of OECD countries have entry regulations that empower local authorities to decide on store entry. However, the regulations differ substantially across countries (Boylaud and Nicoletti, 2001; Griffith and Harmgart, 2005; Schivardi and Viviano, 2011). While some countries strictly regulate large entrants, more flexible zoning laws exist, for instance, in the U.S. (Pilat, 1997).

The Swedish Plan and Building Act (PBA) regulates the use of land and water and buildings. The PBA consists of the planning requirements for land and water areas as well as buildings. The ultimate goal of PBA is to promote equal and adequate living conditions and a lasting sustainable environment for today and future generations. The regulation contains two documents/plans: (i) the comprehensive plan and (ii) the detailed development plan. Municipalities are required to have a comprehensive plan that covers the entire municipality and that guides decisions regarding the use of land, water areas and the built environment. The comprehensive plan records public interests and national interests. Municipalities also have to provide detailed development plans that cover only a fraction of the municipality. Municipalities are divided into smaller areas. These plans indicate and set limits on the use and design of public spaces, land and water areas.

The purpose of the comprehensive plan is to provide an attractive public environment that is sustainable. It is the basis for decisions regarding the use of land, water and the development and preservation of buildings. It reflects the public interest and addresses important environmental and risk factors that must be taken into account in the planning of any endeavor. Necessary features include the housing needs of the municipal inhabitants, the protection of valuable natural and cultural environments, and providing inhabitants with access to services.

The detailed development plan consists of a map with text that indicates what, where and how one is allowed to build, as well as appropriate uses for the area. For instance, it indicates the appropriate design and use of housing, nature and water areas. Other examples include construction rights for real estate including the size and form of structures, the possibility of opening a restaurant, work places and businesses, housing, hotels, housing (villa or apartments), pre-schools, elementary schools, health care, energy- and water services, parks, streets, squares, etc.

The detailed development plan indicates whether retail stores are allowed. The right to open

\footnotetext{
${ }^{11}$ The empirical findings remain robust when constructing market shares using sales instead of quantity (Section 7).
} 
and operate a retail food store is addressed in the detailed development plan. The PBA empowers the country's 290 municipalities to decide on applications for new entrants. Each store seeking to enter the market is required to file a formal application with the local government. For the entry to occur, the municipality can accept a new detailed development plan or make changes in an existing one. First, in the application, the store must state the purpose of the activity: retail, housing, offices, manufacturing, or other. Second, the store must describe the main purpose of its activity and what it is to contain, e.g., a new building of a certain size, wholesale provision with trucks, parking places and is obligated to be as detailed as possible. Before the new detailed development plan is approved, it must be made publicly available. Inhabitants of the municipality are allowed to express their opinions and views on the proposed changes. If some do not agree with the proposed plan, they can appeal. The municipality must then perform a new evaluation and look for alternative solutions to the question at hand.

When a retail store seeks to enter a local market, the municipality evaluates the consequences for exit, prices, local employment, availability of store types and product assortments for different types of consumers, purchasing patterns and purchasing trips, consumer travel behavior, traffic (e.g., generated traffic per square meter of the new sales space) including the effect it has on noise and air pollution for nearby consumers, as well as the number of individuals who will be affected - probable health effects, risk evaluations, broader environmental issues, increased distance to the store, parking, water, energy supply, etc.

In addition, the municipal council must evaluate the positive and negative consequences of the new entrant for different inhabitants, the environment, traffic, public transport, safety, etc. The municipality must consider whether new bus lines are necessary, as well as walking and biking paths. This is to ensure each consumer in the municipality has access to different types of stores, a broad product assortment and reasonable prices. A store entrant is prohibited from hindering real estate developments that will be useful for the public interest, i.e., housing, places of work, traffic infrastructure and leisure environments. The municipal council evaluates and gives an overall assessment of the trade-offs between the public interest and private retail interests. This assessment is based on contingency analysis, an investigation of alternative solutions and developments, and strategic judgement. It is important to evaluate the effects that accepting a new detailed development plan and changing an existing one on the public interest.

All stores are regulated by the PBA in Sweden, in contrast with, for example, the U.K., which ex- 
plicitly focuses on regulating large stores (Maican and Orth, 2015b; Sadun, 2015). Inter-municipality questions of entry are addressed by the 21 county administrative boards. The PBA is considered one of the major barriers to entry and is the cause of a diverse array of outcomes, e.g., price levels, across municipalities (Swedish Competition Authority, 2001:4). Several reports stress the need to better analyze how entry regulation affects market outcomes (Pilat, 1997; Swedish Competition Authority, 2001:4; Swedish Competition Authority, 2004:2). Online Appendix A describes the PBA in greater detail.

Our study shares a common feature with previous works on entry regulations in that it acknowledges that there is no single ideal measure of regulatory stringency in local markets. Drawing heavily on previous work on land-use and entry regulations (Bertrand and Kramarz, 2002; Schivardi and Viviano, 2011; Suzuki, 2013; Turner et al., 2014), we collect data from several sources. As our main measure of regulatory stringency, we access data on political preferences, i.e., the share of non-socialist seats in the local government (Bertrand and Kramarz, 2002; Schivardi and Viviano, 2011). The exogeneity of political preferences in measuring regulatory stringency relies on local economic issues' not determining future election outcomes. In Sweden, we believe it is reasonable to rely on the assumption that land-use issues do not determine the outcomes of local elections. Swedish municipalities have numerous responsibilities. Childcare, schooling and elderly care are the main spending areas likely to have a greater influence on voter decisions. We expect that in the case of Sweden, we expect that non-socialist local governments are more liberal regarding new entry. ${ }^{12}$ This is confirmed by simple reduced-form regressions. Overall, 117 of the 290 municipalities have had a non-socialist local government for at least one of the years in our study period. In local government (municipal) elections, there are two shifts in the number of seats during the study period. The number of markets with a non-socialist local government increases over time: 57 (2001-2002), 104 (2003-2006), and 102 (2007-2008).

In addition to political seats, we have data on the number of the applications approved (PBA) by local authorities for each municipality and year. This includes applications to change land-use plans and the total number of existing land-use plans. ${ }^{13}$ The data are collected by the Swedish

\footnotetext{
${ }^{12}$ The Social Democratic Party collaborates with the Left Party and the Green Party. The non-socialist group consists of the Moderate Party, most often together with the Liberal Party, Christian Democrats, and the Center Party. The Center Party is traditionally strong in rural areas and is not expected to be more liberal towards entry of new stores. For our purposes, we therefore only consider the Moderate Party, the Liberal Party and Christian Democrats in the non-socialist group.

${ }^{13}$ In addition, we have data on the number of approved PBA applications permitting the entry of retail stores. A high number of approved applications that allow retail stores to enter the market indicates a more liberal application of the PBA. The data are collected by surveys of 163 of the 290 municipalities and are available for three time periods:
} 
Mapping, Cadastral and Land Registration Authority (Lantmäteriet). Municipalities with a nonsocialist majority approve more PBA applications. The correlation between non-socialist seats and the number of approved PBA applications in local markets is 0.6.

To measure local market regulation, we use the share of political seats alone and index variables constructed using the share of political seats and various measures of the number of approved PBA applications (Suzuki, 2013; Turner et al., 2014). By construction, the index variables are not sensitive to the size of the local market. Specifically, we use an index in which half the weight is the share of non-socialist seats in local governments, one quarter is the number of approved applications over the total number of stores and one quarter is the number of approved applications over the number of existing land-use plans. The higher the index is, the more the liberal regulations are. The lower and upper bounds of the index are 0.032 and 1.28 , respectively. The median is 0.28 , and the standard deviation is approximately 0.14 . We define municipalities as having restrictive (liberal) regulations if the index is below (above) the median. To keep the exposition tractable, we report results using only one index definition. The robustness checks (Section 7) and online Appendix H discuss results when only using political seats or alternative definitions of the regulation index to measure regulation.

Descriptive statistics. Table 1 shows aggregate statistics for the 2001-2008 period. The total number of stores decreases by 16 percent to 5,240 at the end of the period. While total sales increase by more than 24 percent, the total number of square meters increases by only about 10 percent. The share of large stores increases by 3.5 percentage points to nearly 22 percent in 2008 . Large stores account for the majority of the sales and sales space. Their sales increase by 3.8 percentage points to 61.8 percent in 2008 , whereas their sales space increases by 2.7 percentage points to 60.5 percent. Thus, large stores experienced higher growth in sales than in sales space or the number of stores, indicating improvements in efficiency. The opening hours are generally long in Sweden (e.g., 8-22), and has not changed dramatically during the study period. The total number of entrants is fairly constant over time, with the number of exits being slightly less than twice the number of entrants. The majority of entrants and exits are small stores (online Appendix B).

Figure 1 shows that the number of small stores decreases by approximately 20 percent to 3,215 in 2008; however the number of large stores is fairly constant. There is a decline in the total number 1987-1992, 1992-1996, and 1997-2000 (Swedish Competition Authority, 2001:4). The survey was unfortunately not performed during our study period, i.e., 2001-2008. Importantly, the correlation between the number of approved applications for retail stores and the total number of approved applications is as high as 0.83 . 
of stores affiliated with three of the main firms: 28 percent for ICA, 26 percent for Coop, and 11 percent for Axfood. The opposite trend is observed for Bergendahls and hard discounters. The number of large stores increases for ICA and Bergendahls and is fairly constant for Coop, whereas it decreases for Axfood and Others. There is a substantial decline in the number of stores affiliated with ICA, Coop, and Others, whereas the changes are smaller in magnitude for small stores that are affiliated with Axfood. Figure 2 shows that the total number of entrants increases until 2005 and then declines, whereas the number of stores that exit peaks in 2004. Figure 3 shows that the entry and exit rates are correlated over time.

Table 2 presents entry and exit rates across markets and owners for the 2002-2007 period. On average, the exit rate is two to three times higher than the entry rate, but the standard deviations are approximately the same. The mean exit rate varies between 0.03 and 0.07 , with a standard deviation of $0.05-0.08$. The mean entry rate ranges between 0.01 and 0.04 , and the standard deviation is somewhat lower than that for exit. As entry and exit do not occur in all markets in a given year, we observe variation in the upper percentiles. For example, the entry rate for the 75 th percentile varies substantially over time (0-0.06).

Exit occurs in between 9 and 40 percent of the markets in a given year, while the corresponding number for entry is $15-30$ percent. The overall correlation between the entry and exit rates is 0.04 , whereas the correlation between the number of entrants and the number of exits is 0.43. If we exclude the three metropolitan areas (Stockholm, Gothenburg, and Malmö), the correlation is weaker at 0.17 . The positive correlation between entry and exit supports our approach of using a dynamic model.

Descriptive patterns that link to structural results. In our sample, the median store size is approximately 215 square meters for small stores and approximately 1,725 square meters for large stores; i.e., a median large store is about eight times larger than a small store. In terms of sales, a median large store sells about ten times more than a median small store. The sales per square meter of a median large store are approximately 21 percent higher than those for a median small store. These figures emphasize the importance of estimating costs separately for small and large stores, as we do in this paper. 


\section{A dynamic oligopoly model}

To evaluate the impact of entry regulation on market structure dynamics and welfare, we build a dynamic game model based on Pakes et al. (2007) that accounts for product differentiation in store type/location and incorporates a discrete choice demand model. The players in a local market consist of a finite set of incumbent stores $\mathbf{J}^{c}$ and a finite set of potential entrant stores $\mathbf{J}^{e}$. A specific player is denoted $j^{c} \in \mathbf{J}^{c}$ for incumbents and $j^{e} \in \mathbf{J}^{e}$ for potential entrants. We consider a dynamic game of entry and exit in discrete time $(t=1,2, \ldots, \infty)$ in a market $m \in \mathcal{M}$, where $\mathcal{M}$ is a finite set of local markets. In the beginning of each period, incumbents and potential entrants choose their actions (whether to exit and whether to enter). Next, the stores that decide to operate simultaneously choose prices. Finally, consumers choose where to shop. In this section, we discuss stores' dynamic entry and exit decisions. Section 4.1 discusses consumers' decisions. In what follows, we describe the events taking place in every period in a local market. For notational simplicity, the presentation omits the market index $m$.

States. A player is described by a vector of state variables $\mathbf{s}_{t}=\left(n_{z t}, \mathbf{n}_{-z t}, \mathbf{y}_{t}\right)$ that consists of the number of active stores of each type in a local market, $\left(n_{z t}, \mathbf{n}_{-z t}\right), z \in z=\{1, \cdots, Z\}$, and exogenous profit shifters that are specific to each type $\mathbf{y}_{t}$. The vector $\mathbf{n}_{-z t}$ includes the number of each store type except $z$, i.e., $\mathbf{n}_{-z t}=\left\{n_{1}, \cdots, n_{z-1}, n_{z+1}, \cdots, n_{Z}\right\}$. For example, in case of two types (small and large), the state space is $\mathbf{s}=\left(n_{\text {small }}, n_{\text {large }}, \mathbf{y}\right)$, where $n_{\text {small }}$ and $n_{\text {large }}$ is the number of small and large stores, respectively. The state variables $\mathbf{s}_{t}$ are commonly observed by all players and the econometrician. The profit shifters $\mathbf{y}_{t}$ have finite support, and the states $\mathbf{s}_{t}$ are bounded. Players also receive privately observed payoff shocks. In every period, each incumbent $j^{c}$ of type $z$ receives a draw of the fixed cost $\phi_{j z t}^{c}$ from the common distribution $F^{\phi_{z}}$. In every period, each potential entrant $j^{e}$ of type $z$, receives a draw of the entry cost $\kappa_{j z t}^{e}$ from the common distribution $F^{\kappa_{z}}$. Fixed costs and sunk costs are drawn from known distributions that are observed by all players. Fixed costs and sunk costs are i.i.d. across both players and time periods. All stores of type $z$ are identical up to the draw of the fixed cost and entry fee. All parameters of the distributions of fixed costs $F^{\phi_{z}}$ and sunk costs $F^{\kappa z}$ are collected in $\boldsymbol{\theta}$.

Actions. Players simultaneously decide their actions in the beginning of each period. Actions are taken after players observe the commonly known state variables and the private cost shocks. Each incumbent $j^{c}$ chooses whether to continue to operate with store type (or in location) $z \in Z$ or exit. Incumbents pay their fixed cost in the next period if they continue. Each potential entrant $j^{e}$ 
decides whether to enter a store of type $z \in \mathcal{Z}$.

The set of potential entrants are short-lived, and they will be replaced with a new set of potential entrants once they decide not to enter the market. Entrants' decisions are made one period ahead of the start of operation, which implies that we can obtain continuation and entry values that do not depend on entry costs. All incumbents and potential entrants form beliefs of the entry and exit of their rivals.

State transition. The number of stores of type $z$ evolves endogenously over time according to $n_{z t+1}=n_{z t}+e_{z t}-x_{z t}$, where $n_{z t}$ is the number of incumbents and $e_{z t}$ and $x_{z t}$ are the number of entrants and exits. The exogenous profit shifters that include both demand and variable costs are public information to firms and evolve exogenously according to a first-order Markov process $\mathbb{P}\left(\mathbf{y}_{t+1} \mid \mathbf{y}_{t}\right)$.

Per-period profits. Each store's per-period variable profit $\pi_{z}\left(\mathbf{s}_{t} ; \boldsymbol{\theta}\right)$ is commonly observed at the end of each period after all actions are taken, where $\pi_{z}(\cdot)$ is bounded and converges to zero as the numbers of incumbents grows. Section 4.1 discusses the computation of per-period profits $\pi_{z}(\cdot)$ using a discrete choice demand system, a marginal cost function specification, and an equilibrium assumption.

Local markets. We assume that local markets are independent, i.e., a separate game is played in each local market. This assumption implies that there is no interdependence between entry decisions across local markets. Hence, entry and exit decisions in one market do not depend on entry and exit decisions in any other market. It does not matter whether two municipalities are neighbors. For instance, stores of the same owner are not allowed to benefit from economies of scale, scope or density across local markets (e.g., joint benefits from logistics and advertising). The main reason for using this assumption is to simplify estimation of the dynamic game. There are a few papers that account for entry into multiple markets, e.g., Jia (2008); Nishida (2014); Holmes (2011). A common characteristic of these studies is that they only consider two to three players.

Equilibrium. Incumbents and potential entrants make simultaneous moves and form expectations of the entry and exit of their rivals. In equilibrium, these expectations must be consistent with the stores' actual behavior. The incumbents' expectations of rival incumbents' behavior are identical for all rivals of the same type. Similarly, all potential entrants have the same probability of entering with a given type. The solution concept is a Markov Perfect Equilibrium. We assume that the same equilibrium is played in all local markets. This assumption allows us to compute conditional choice 
probabilities and transition matrices using a pooled sample from different markets. However, more than one equilibrium might exist. We acknowledge that the assumption of a single equilibrium in the data, which is commonly used in empirical applications, is restrictive. ${ }^{14}$ Inference on multiple equilibria for this class of dynamic games has, however, not yet been addressed in the literature. ${ }^{15}$

We assume that players' strategies are pure Markovian. The action of one player can thus be expressed as a function of only the privately observed payoff shocks and the commonly observed state variables. Because we focus on stationary Markov strategies, we do not consider the time index $t$ in what follows.

We do not allow stores to invest or change owners or formats. That store concepts in retail are rather uniform justifies this assumption. Nevertheless, the proposed dynamic model allows us to understand asymmetries in strategic interactions between small and large stores and how these influence the dynamics of the market structure on the supply side.

Incumbents. The value function of an incumbent store of type $z$ is given by the Bellman equation

$$
V_{z}\left(\mathbf{s}, \phi_{z} ; \boldsymbol{\theta}\right)=\pi_{z}(\mathbf{s} ; \boldsymbol{\theta})+\max \left\{\beta V C_{z}(\mathbf{s} ; \boldsymbol{\theta})-\beta \phi_{z}, 0\right\},
$$

where $\pi_{z}(\cdot)$ is the profit function; $V C_{z}(\cdot)$ is the continuation value; $\phi_{z}$ is the fixed cost; and $0<\beta<1$ is the discount factor. Incumbents know their fixed $\operatorname{cost} \phi_{z}$ but not the number of entrants and exits prior to making their decisions. The optimal policy for an incumbent is to exit if the draw of the fixed cost is larger than the expected future profits, which yields the probability of exit $p_{z}^{x}(\mathbf{s})=$ $\operatorname{Pr}\left(\phi_{z}>V C_{z}(\mathbf{s} ; \boldsymbol{\theta})\right)=1-F^{\phi_{z}}\left(V C_{z}(\mathbf{s} ; \boldsymbol{\theta})\right)$. Incumbents that continue obtain the continuation value

$$
\begin{aligned}
V C_{z}(\mathbf{s} ; \theta) & =E_{\mathbf{s}^{\prime}}^{c}\left[\pi_{z}\left(\mathbf{s}^{\prime} ; \boldsymbol{\theta}\right)+E_{\phi_{z}^{\prime}}\left[\max \left\{\beta V C_{z}\left(\mathbf{s}^{\prime} ; \boldsymbol{\theta}\right)-\beta \phi_{z}^{\prime}, 0\right\}\right]\right] \\
& =E_{\mathbf{s}^{\prime}}^{c}\left[\pi_{z}\left(\mathbf{s}^{\prime} ; \boldsymbol{\theta}\right)+\beta\left(1-p_{z}^{x}\left(\mathbf{s}^{\prime}\right)\right)\left(V C_{z}\left(\mathbf{s}^{\prime} ; \boldsymbol{\theta}\right)\right.\right. \\
& \left.\left.-E\left[\phi_{z}^{\prime} \mid \phi_{z}^{\prime} \leq V C_{z}\left(\mathbf{s}^{\prime} ; \boldsymbol{\theta}\right)\right]\right)\right]
\end{aligned}
$$

where $\mathbf{s}^{\prime}=\left(n_{z}^{\prime}, \mathbf{n}_{-z}^{\prime}, \mathbf{y}^{\prime}\right)$ and the expectation $E_{\mathbf{s}^{\prime}}^{c}[\cdot]$ uses the continuing stores' perceptions of the future values of the state variables. If we assume that $\phi_{z}$ follows an exponential distribution, we

\footnotetext{
${ }^{14}$ Pakes et al. (2007) claim that the correct equilibrium will be selected in sufficiently large samples. The model requires consistent transition probabilities to be constructed only once based on what is observed in the data. In markets with various structural changes over time, we might not obtain consistent transition probabilities if the period is not sufficiently long.

${ }^{15}$ For details and explanations, see Pakes et al. (2007). Otsuy et al. (2015) discuss the existence of multiplicity of equilibria in empirical applications and propose several statistical tests to examine the null hypothesis that data from distinct markets can be pooled.
} 
obtain $E\left[\phi_{z}^{\prime} \mid \phi_{z}^{\prime} \leq V C_{z}\left(\mathbf{s}^{\prime} ; \boldsymbol{\theta}\right)\right]=\sigma_{z}-V C_{z}\left(\mathbf{s}^{\prime}\right)\left[p_{z}^{x}\left(\mathbf{s}^{\prime}\right) /\left(1-p_{z}^{x}\left(\mathbf{s}^{\prime}\right)\right)\right]$. Substituting this into (2), we obtain

$$
V C_{z}(\mathbf{s} ; \boldsymbol{\theta})=E_{\mathbf{s}^{\prime}}^{c}\left[\pi_{z}\left(\mathbf{s}^{\prime} ; \boldsymbol{\theta}\right)+\beta V C_{z}\left(\mathbf{s}^{\prime} ; \boldsymbol{\theta}\right)-\beta \sigma_{z}\left(1-p_{z}^{x}\left(\mathbf{s}^{\prime}\right)\right)\right],
$$

where $\sigma_{z}$ is a parameter in the exponential distribution that represents the inverse of the mean.

Entrants. Potential entrants maximize the expected discounted future profits and enter if they can cover their sunk costs. They start to operate in the next period. The value of entry is

$$
V E_{z}(\mathbf{s} ; \boldsymbol{\theta})=E_{\mathbf{s}^{\prime}}^{e}\left[\pi_{z}\left(\mathbf{s}^{\prime} ; \boldsymbol{\theta}\right)+\beta V C_{z}\left(\mathbf{s}^{\prime} ; \boldsymbol{\theta}\right)-\beta \sigma_{z}\left(1-p_{z}^{x}\left(\mathbf{s}^{\prime}\right)\right)\right]
$$

where $p_{z}^{x}\left(\mathbf{s}^{\prime}\right)$ is a potential entrant's perceptions of the number of exits of each type conditional on entering the market and $E_{\mathbf{s}^{\prime}}^{e}[\cdot]$ indicates the entrants' expectations of future state variables. Entry occurs if the draw from the distribution of sunk costs is smaller than the value of entry, which results in the probability of entry $\operatorname{Pr}\left(\kappa_{z}<V E_{z}(\mathbf{s} ; \boldsymbol{\theta})\right)=F^{\kappa_{z}}\left(V E_{z}(\mathbf{s} ; \boldsymbol{\theta})\right)$.

Potential entrants choose to operate a store of type $z$ if the expected profits are higher than those for all other types and the outside option. Thus, first, the entry value must be larger than the draw of the entry cost. In addition, the type decision must yield the highest expected discounted future profits among all type alternatives:

$$
\begin{gathered}
\beta V E_{z}(\mathbf{s} ; \boldsymbol{\theta}) \geq \kappa_{z} \\
\beta V E_{z}(\mathbf{s} ; \boldsymbol{\theta})-\kappa_{z} \geq \beta V E_{z^{\prime}}(\mathbf{s} ; \boldsymbol{\theta})-\kappa_{z^{\prime}} \quad \forall \quad z^{\prime} \in z .
\end{gathered}
$$

We assume that entry costs follow a unimodal distribution with the general density function given by

$$
f(\kappa=\mu)=a^{2}\left(\mu-\frac{1}{a}\right) \exp \left(-a\left(\mu-\frac{1}{a}\right)\right),
$$

for $\mu \in(1 / a, \infty)$, where the parameter $a(a>0)$ defines the boundary support for the entry cost $\kappa$. Because of the boundary support, there is no entry if the number of incumbents is very large. The entry costs for small $\left(\kappa_{\text {small }}\right)$ and large stores $\left(\kappa_{\text {large }}\right)$ in a local market are assumed to be independent, where $\kappa_{\text {small }}$ and $\kappa_{\text {large }}$ follow unimodal distributions with parameters $a_{1}\left(a_{1}>0\right)$ and $a_{2}\left(a_{2}>0\right)$, respectively. We expect higher entry costs for large stores because they require more 
land and building permissions and influence the traffic and the environment, i.e., $\kappa_{\text {large }}>\kappa_{\text {small }} .{ }^{16}$ The parameters $a_{1}$ and $a_{2}$ are estimated in the second stage together with $\sigma_{z}$.

We now define the continuation values, profits, and exit probabilities as vectors and define a matrix of transition probabilities $\boldsymbol{W}_{z}^{c}$ that indicates the transition from state $\mathbf{s}$ to state $\mathbf{s}^{\prime} \neq \mathbf{s}$ for type $z$

$$
\boldsymbol{V} \boldsymbol{C}_{z}(\boldsymbol{\theta})=\boldsymbol{W}_{z}^{c}\left[\boldsymbol{\pi}_{z}+\beta \boldsymbol{V} \boldsymbol{C}_{z}(\boldsymbol{\theta})-\beta \sigma_{z}\left(1-\boldsymbol{p}_{z}^{x}\right)\right],
$$

which implies that

$$
\boldsymbol{V} \boldsymbol{C}_{z}(\boldsymbol{\theta})=\left[I-\beta \boldsymbol{W}_{z}^{c}\right]^{-1} \boldsymbol{W}_{z}^{c}\left[\boldsymbol{\pi}_{z}-\beta \sigma_{z}\left(1-\boldsymbol{p}_{z}^{x}\right)\right],
$$

where $I$ is the identity matrix. Using nonparametric estimates of $\boldsymbol{W}_{z}^{c}$ and $\boldsymbol{p}_{z}^{x}$ from the data, we can obtain an estimate of the value function at each state. There is no dependence over time in the transition probabilities. ${ }^{17}$ For potential entrants, the value of entry is

$$
\boldsymbol{V} \boldsymbol{E}_{z}(\boldsymbol{\theta})=\boldsymbol{W}_{z}^{e}\left[\boldsymbol{\pi}_{z}+\beta \boldsymbol{V} \boldsymbol{C}_{z}(\boldsymbol{\theta})-\beta \sigma_{z}\left(1-\boldsymbol{p}_{z}^{x}\right)\right],
$$

where $\boldsymbol{W}_{z}^{e}$ is the transition matrix that yields the probability that an entrant starts operating at $\mathbf{s}^{\prime}$ conditional on entering in state s. Online Appendix D provides details regarding the construction of the transition matrices.

Comparisons to alternative approaches: static and dynamic. The model rests on several assumptions that are already grounded in the POB-type models, e.g., cost draws are i.i.d. and timing assumptions on entry. Our model differs from previous work based on the POB framework in the following ways: First, we account for heterogeneous stores. Second, we use a demand system and data on store-level prices to recover variable profits and welfare measures for each state, which allows us to understand the dynamic implications of entry regulation for welfare.

We can compare our dynamic model with static, two-period models that allow for heterogeneous types. The static entry models with identical firms developed by Bresnahan and Reiss (1987) and Bresnahan and Reiss (1991) are extended to account for heterogeneous players by Mazzeo (2002) and Seim (2006) (Berry and Reiss, 2007 survey this literature). A static analysis based on cross-sectional

\footnotetext{
${ }^{16}$ Previous versions of the paper allowed for a correlation in entry costs, i.e., $\kappa_{\text {large }}=\kappa_{\text {small }}+\mu$, where $\kappa_{\text {small }}$ and $\mu$ follow unimodal distributions with parameters $a_{1}\left(a_{1}>0\right)$ and $a_{2}\left(a_{2}>0\right)$, respectively. The main benefit of allowing for a correlation in entry costs is that by construction $\kappa_{\text {large }}>\kappa_{\text {small }}$. However, our empirical results are not dependent on this assumption.

${ }^{17}$ While we add various market controls when computing variable profits using a discrete choice demand system, it is difficult to control for the possible presence of serially correlated unobservables in our dynamic framework. See Takahashi (2015) for a dynamic model of exit that controls for correlated unobservables.
} 
data cannot separately identify sunk costs from fixed costs; in addition, it is unable to explain the descriptive patterns of entry and exit that we observe in our data and requires the market structure to be in long-run equilibrium. ${ }^{18}$ Our model differs from the static models of heterogeneous firms in the following ways: First, we distinguish short-run profits from long-run profits (continuation and entry values). Second, we distinguish sunk costs from fixed costs. Third, we allow for transitions in the market structure over time and let the prior market structure and the number of stores influence the future market structure. In summary, a dynamic model is necessary if one wishes to quantify how profitability and market structure change due to entry, exit and policy modifications.

There are recent studies that combine static entry models with a static demand system (e.g., Gowrisankaran and Krainer, 2011) and use dynamic models of demand (e.g., Gowrisankaran and Rysman, 2012). We contribute to this literature by jointly considering a dynamic entry and exit setting with a static demand framework.

\section{Identification and estimation}

The empirical implementation proceeds in four steps: First, we estimate a static discrete choice demand model that is used to construct variable profits for each store. We believe it is reasonable to assume a static demand system for retail food because consumers purchase food products, which are of limited durability, on a frequent basis. We use the Nash price equilibrium system from the demand system together with predicted values for marginal cost to compute variable profits for each store type for all possible states. The main advantage of this approach is that we are able to compute counterfactual prices, profits, and welfare measures. Second, we estimate the transition probabilities, which are used to compute the continuation and entry value functions. Third, we estimate the cost distributions (fixed and sunk) for each store type in liberal and restrictive markets. Fourth, we calculate welfare measures and evaluate equilibrium outcomes under a number of alternative entry regulation regimes.

\footnotetext{
${ }^{18}$ Applying a static model to cross-sectional data from 2001 may therefore yield substantially different results than using data from 2008, where there are 16 percent fewer stores and 3.5 percentage points higher share of large stores.
} 


\subsection{Demand and profits}

Demand estimation. To construct variable profits, we rely on a static discrete choice demand model. ${ }^{19}$ We adopt a nested logit specification with correlation $\tau$ across stores that belong to the same group of store type $z \in Z$. The arguments for using store types as nests rely on the assumption that store type likely influences consumer choice. Consumers acknowledge that stores differ and perceive similar store types to be closer substitutes. This allows preferences to be correlated across stores of a certain type. In accordance with Berry (1994), the utility of consumer $i$ of store $j$ in local market $m$ is given by

$$
u_{i j m t}=\delta_{j m t}+\zeta_{i z m t}+(1-\tau) \epsilon_{i j m t},
$$

where $\epsilon_{i j m t}$ is identically and independently distributed extreme value, $\zeta_{i z m t}$ is common to all stores in group $z$ and has a distribution function such that if $\epsilon_{i j m t}$ is a random variable, $[\zeta+(1-\tau) \epsilon]$ is extreme value distributed with $\tau \in[0,1]$ measuring the within-group correlation in idiosyncratic preferences. ${ }^{20}$ Let $\delta_{j m t}=\mathbf{x}_{j m t} \beta-\alpha p_{j m t}+\eta_{f}+\eta_{m}+\xi_{j m t}$, where $\mathbf{x}_{j m t}$ are control variables such as the log of store size $\left(m^{2}\right)$, average local market income, and income squared; $p_{j m t}$ is the price of the product basket; $\eta_{f}$ are dummies for the main firms (ICA, Axfood, Coop, and Bergendahls); and $\eta_{m}$ are fixed effects for local markets. The remaining demand shocks $\xi_{j m t}$ are not correlated across store types and markets and could include a store's local advertising, for example. Integrating out over the idiosyncratic preferences yields the estimable demand equation

$$
\ln \left(s_{j m t}\right)-\ln \left(s_{0 m t}\right)=\mathbf{x}_{j m t} \beta-\alpha p_{j m t}+\tau \ln \left(s_{j m t \mid z}\right)+\eta_{f}+\eta_{t}+\xi_{j m t},
$$

where $s_{j m t}$ is the market share of store $j$ constructed using the quantity of a product basket that a store sells in year $t$ in market $m$, i.e., $q_{j m t}=s a l e s_{j m t} / p_{j m t}$ and $s_{j m t}=q_{j m t} / \sum_{k \in m, k \neq j} q_{k m t} . s_{j m t \mid z}$ is the within-group share of store $j$ in group $z$ in market $m$ and $s_{0 m t}$ is the market share of the outside option, which is defined as buying food from stores not affiliated with the four main firms. We form moment conditions on $\xi_{j m t}$ to identify $\alpha, \beta$ and $\tau$.

\footnotetext{
${ }^{19}$ An alternative is to use accounting (book-value) profits. Generally, accounting (book-value) profits are viewed with skepticism (Scherer and Ross, 1990). For robustness, we have checked and found that the constructed profits are in accordance with the aggregated profits reported by Statistics Sweden (SCB).

${ }^{20}$ Although the nested logit demand model relaxes the logit assumption of uncorrelated consumer preferences across stores by allowing preferences to be correlated across stores within a group (small or large), it nevertheless imposes restrictions on cross-price elasticities, which are symmetric within a group (Grigolon and Verboven, 2014). Berry et al. (1995) and Berry et al. (2004) provide rich discrete choice frameworks to model demand.
} 
Store profits. The variable profits of store $j$ are given by

$$
\pi_{j m t}=\left(p_{j m t}-m c_{j m t}\right) M_{t} s_{j m}(\mathbf{p}, \mathbf{x} ; \boldsymbol{\psi})
$$

where $m c_{j m t}$ is the marginal cost of store $j$ in market $m ; M_{t}$ is the total market size, i.e., the number of consumers that purchase the food product (our product basket); $\mathbf{p}$ is the price vector; $\mathbf{x}$ is the store characteristics matrix; and $\boldsymbol{\psi}=(\alpha, \beta, \tau)$ represents the parameters to be estimated. ${ }^{21}$

We assume that stores compete in prices, which determine the basket price, and that $p_{j m t}$ is the result of a pure strategy Nash equilibrium. The fact that individual stores determine their own prices in Sweden supports this assumption. In the standard nested logit specification, derived in Berry (1994), the price minus marginal cost takes a simple analytical form

$$
p_{j m t}-m c_{j m t}=\left[\frac{(1-\tau)}{\alpha} /\left[1-\tau s_{j m t \mid z}-(1-\tau) s_{j m t}\right]\right]
$$

Identification. To estimate equation (11), we require instruments for the endogenous variables price $p_{j m t}$ and the within-group share $s_{j m t \mid z}$. There is variation in prices across store types, firms, markets and years. As instruments for $p_{j m t}$, we use the main cost shifters for retail food stores $\left(\mathbf{w}_{j m t}\right)$, which are the labor and logistics costs. We proxy for these costs using average wages and the distance to the nearest distribution center for each store type, firm and market. These instruments are correlated with the store's price because of the service production costs, and they do not include store-specific demand shocks. ${ }^{22}$ As an instrument for $s_{j m t \mid z}$, we use the $\log$ of the number of stores of each type in the local market. In addition, we use the average number of stores of each type in other local markets. Moreover, any function of these variables is a valid instrument. The parameters $\beta$ are identified using moment conditions on $\mathbf{x}_{j m t}$. Section 7 discusses the robustness results using additional identification strategies for the demand equation.

Equilibrium prices. We use the Nash equilibrium condition (first-order condition of (12)) together with the estimated information about the marginal cost $m c_{j m t}$ to compute equilibrium prices. Our contribution to previous work on POB-type models is that we can calculate counterfactual prices,

\footnotetext{
${ }^{21}$ Using quantity, the variable profits can be also computed as $\pi_{j m t}=\left(p_{j m t}-m c_{j m t}\right) q_{j m t}(\mathbf{p}, \mathbf{x} ; \boldsymbol{\psi})$, where $q_{j m t}$ is the quantity of food product baskets sold by store $j$.

${ }^{22}$ The average prices of stores of the same type in other local markets can also be used as an instrument for $p_{j m t}$ (Hausman, 1997; Nevo, 2001; Hendel and Nevo, 2006). This instrument is correlated with the store's price because of the service production costs and is valid if there are no national demand shocks.
} 
profits, and measure social welfare due to changes in entry regulation. The price $p_{j m t}$ and market share $s_{j m t}$ are not observed for potential (hypothetical) entrants, but they can be computed using extrapolated marginal cost $m c_{j m t}$ from the linear specification $m c_{j m t}=\mathbf{x}_{j m t}^{\prime} \gamma+\epsilon_{j m t}$, where the vector $\mathbf{x}_{j m t}^{\prime}$ includes store-type dummies, market fixed effects, and average wage that are likely to be exogenous or predetermined (online Appendix F). The fitted values are $\hat{m} c_{j m t}=\hat{m} c_{j^{\prime} m t}$ if stores $j$ and $j^{\prime}$ belong to the same store type $z$ (i.e., small or large). The equilibrium prices in a given state (market configuration) are computed by numerical iteration using the first-order condition and fitted values of marginal cost:

$$
p_{j m t}^{l+1}=-s_{j m t}\left(\mathbf{p}^{l}, \mathbf{x} ; \boldsymbol{\psi}\right)\left(\frac{\partial s_{j m t}\left(\mathbf{p}^{l}, \mathbf{x} ; \boldsymbol{\psi}\right)}{\partial p_{j m t}}\right)^{-1}+\hat{m} c_{j m t}
$$

where $p^{l}$ is the price at iteration $l$ and $l=0,1,2, \cdots$. We use the observed values of price as the initial values of $p_{j m t}^{l} .{ }^{23}$ We find that numerical iteration converges fast. The recovered information about equilibrium prices and marginal costs allows us to compute the variables profits for each state in the state space.

\subsection{Value functions and transitions between states}

To compute the continuation values for incumbents $\left(\boldsymbol{V} \boldsymbol{C}_{z}\right)$ and entrants $\left(\boldsymbol{V} \boldsymbol{E}_{z}\right)$, we need to calculate the expected discounted future profits that the store would obtain from counterfactual future states. The transition probability matrices $\left(\boldsymbol{W}_{z}^{c}\right)$ and $\left(\boldsymbol{W}_{z}^{e}\right)$ are computed for each store type and local markets with different degrees of entry regulation using the empirical transition probabilities. As explained in Section 2, we define municipalities as having a restrictive (liberal) implementation of the PBA if the regulation index is below (above) the median. The grouping of local markets is considered exogenous to the stores, and we consequently do not attempt to model expected changes in regulations over time (Dunne et al., 2013).

We estimate the transition probabilities using all municipalities in Sweden with a population of fewer than 200,000; i.e., large cities, such as Stockholm, Gothenburg, and Malmö, are excluded. The number of small store types in each market varies between 2 and 55, and there are between 2 and 19 large stores in each market. To simplify the computation of the static Nash-Bertrand equilibrium

\footnotetext{
${ }^{23}$ We obtain $\hat{\xi}_{j m t}$ for stores that are observed in the data and use the average value for stores that are not observed in the data.
} 
given the state space, we use only market size as the third state in the state space. However, other exogenous demand and cost shifters (e.g., wages) are still part of the state space because they enter in the computation of fitted values for the marginal cost at each state. Market size is continuous and part of the state space, and we discretize it in three groups (small, medium, large) based on quantiles to reduce dimensionality of the state space. We analyze 290 local markets over 8 years, and the different configurations of small stores, large stores and the market size index yield a highdimensional state space. The dimensionality of the generated state space is 1,911 states in markets with restrictive entry regulations and 2,916 states in markets with liberal entry regulations. ${ }^{24}$

Online Appendix D presents the technical details used to construct the empirical transition matrices. Pakes et al. (2007) provide a detailed discussion of the advantages of using empirical transition matrices over structural ones. For structural transitions, we need to impute entry and exit rates for states that are not observed in the data, which might affect the estimation of the cost parameters. However, the precision of the first-stage estimates might be problematic when using empirical probabilities, where we may obtain terminal conditions that are not visited prior to the terminal period. We update these transition probabilities with the average transition probabilities for the cells closest to the terminal cell weighted by the number of times these cells were observed, as POB emphasizes that "smoothing" the value functions is preferable in small samples when the number of states at which the value function need to be estimated is large relative to the observed sample. Smoothing estimators reduce the variance of the estimates of the value functions. In the empirical application, we follow the POB suggestion and estimate the value functions at each state visited. Then, we use smoothing estimators (b-splines/kernels) to obtain the estimates of the value functions at each point that uses the information from nearby points. Therefore, the "smoothed" $V C_{z}$ and $V E_{z}$ are used in the estimation of the cost parameters.

\subsection{Estimation of entry and fixed costs}

The final stage involves parameter estimation of sunk costs $\left(\kappa_{z}\right)$ and fixed costs $\left(\phi_{z}\right)$ for each store type in local markets with restrictive and liberal regulation. The continuation value is computed

\footnotetext{
${ }^{24}$ The dimensionality of the generated state space is determined according to all possible combinations of the number of small stores, the number of large stores and values of the market size index. After the transition matrices are computed, they are retained in memory to increase computational efficiency. Calculating the inverses of the transition matrices is the most demanding computational task. Our Java code uses sparse matrices and parallel computing. For two types, it takes less than one minute to compute all matrices necessary to evaluate the value functions on an ordinary laptop with a dual-core processor.
} 
for each state and is known up to the parameter of the distribution of fixed costs $F^{\phi_{z}}$. The value of entering depends on the entry cost draw from the distribution $F^{\kappa_{z}}$. A minimum distance estimator or indirect inference estimator can be used to estimate the cost parameters. Both estimators yield similar estimates in our application, which is unsurprising because indirect inference is also a GMM estimator. In the case of indirect inference, we use ordinary least squares (OLS) to regress entry and exit probabilities from the data and the model, respectively, on the state variables, i.e., $\mathbf{p}=\mathbf{s} \boldsymbol{\rho}$. We save the estimated coefficients $\boldsymbol{\rho}$ (data) and $\boldsymbol{\rho}(\boldsymbol{\theta})$ (model), where the vector $\boldsymbol{\theta}$ contains the parameters of the cost distributions. The criterion function minimizes the distance between the regression coefficients:

$$
\hat{\boldsymbol{\theta}}=\arg \max _{\boldsymbol{\theta}}[\hat{\boldsymbol{\rho}}-\hat{\boldsymbol{\rho}}(\boldsymbol{\theta})]^{\prime} \mathbf{A}_{R}[\hat{\boldsymbol{\rho}}-\hat{\boldsymbol{\rho}}(\boldsymbol{\theta})]
$$

where $\mathbf{A}_{R}$ is the weighting matrix. ${ }^{25}$ Online Appendix E describes details regarding the estimation. The variance-covariance matrix is estimated using a parametric bootstrap, which is easy to apply because we can use the model to simulate new data and then use it to estimate new values for parameters.

\subsection{Welfare measures}

The welfare in each state, i.e., market configuration, is computed as the discounted sum of profits minus costs plus the consumer surplus

$$
W_{t}\left(n_{z}, \mathbf{n}_{z}, \mathbf{y}\right)=C S_{t}\left(n_{z}, \mathbf{n}_{-z}, y\right)+P S_{t}\left(n_{z}, \mathbf{n}_{-z}, y\right) .
$$

The estimation of the demand system allows us to compute the static consumer surplus for each state. The static consumer surplus $C S_{t}(\cdot)$ in the nested logit model is given by (Small and Rosen, 1981)

$$
C S_{m t}=\frac{1}{\alpha} M \ln \left[1+\sum_{z} n_{z m t} \exp \left(\frac{\delta_{z m t}}{1-\tau}\right)\right]
$$

where $\delta_{z m t}$ and $n_{z m t}$ are the mean utility provided by store type $z$ and the number of stores of type $z$ in market $m$ in period $t$, respectively. Because our model is complete, to obtain discounted

\footnotetext{
${ }^{25} \mathrm{An}$ alternative is to use the minimum distance estimator that minimizes the distance between theoretical and observed probabilities is employed to estimate the cost distribution parameters. Let $\hat{\mathbf{p}}_{0}$ be the vector of exit and entry probabilities that are observed in the data for each type and that are, therefore, used to estimate the transition matrices. The vector of theoretical probabilities $\hat{\mathbf{p}}_{1}$ is obtained from the assumed cost distributions and computed value functions. The minimum distance estimator is defined as: $\hat{\boldsymbol{\theta}}=\arg \max \boldsymbol{\theta}\left[\hat{\mathbf{p}}_{0}-\hat{\mathbf{p}}_{1}(\boldsymbol{\theta})\right]^{\prime} \mathbf{A}_{R}\left[\hat{\mathbf{p}}_{0}-\hat{\mathbf{p}}_{1}(\boldsymbol{\theta})\right]$.
} 
consumer surplus, we use numerical simulation. For each state, we simulate the model $T$ periods and obtain the path of consumer surplus starting with the given state (e.g., $T=100$ years). This allows us to compute discounted consumer surplus in a given state. Then, we repeat the simulations and report the average of discounted consumer surplus. The producer surplus $P S_{t}(\cdot)$ is defined as the sum of discounted surplus for incumbents and entrants. ${ }^{26}$ To compute the welfare the industry level in the empirical application, we sum the welfare $W_{t}\left(n_{z}, \mathbf{n}_{z}, \mathbf{y}\right)$ for the states observed in the data.

\section{Results}

This section discusses the results for the demand estimation, static Nash equilibrium outcome, cost parameters, and the welfare measures of current regulation.

\subsection{Demand estimates}

Table 3 reports the estimates of the demand equation (11) using OLS and two-stage least squares. The first specification (columns 1-2) contains store size $\left(m^{2}\right)$ and dummies for the main firms (ICA, Axfood, Coop, and Bergendahls), whereas the second specification (columns 3-4) adds average local market income and income squared. The price coefficient $(\alpha)$ is positive and significant in all specifications. ${ }^{27}$ As expected, the coefficient is smaller after we control for the endogeneity of price and local market characteristics that shift demand. In the OLS specifications, the coefficient of the within-store-type (group) share is approximately 0.90. It decreases to 0.637 when instrumenting within-type share, which is consistent with the existence of demand shocks that affect both the total demand and the within-type share. The coefficients for store size and the dummies for major firms are positive, as anticipated.

Having obtained the demand estimates, we compute the implied price elasticities. We calculate the unweighted average own- and cross-price elasticities for all markets. Table 4 presents the ownand cross-price elasticities for small and large stores, reporting cross elasticities both within and between store types. Because the average estimated price elasticities are functions of the estimated

\footnotetext{
${ }^{26}$ The computation of producer surplus is straightforward because it translates to already computed value functions $V C$ and $V E$. The producer surplus for potential entrants might be biased because some of the potential entrants will never enter (Collard-Wexler (2013) also discusses this aspect). Given that there are only a few entrants in each state, ignoring producer surplus from entrants has only a minor impact on the overall producer surplus.

${ }^{27}$ Note that the price enters the demand equation (11) with a negative sign.
} 
demand parameters, we use the bootstrap method to compute the standard errors for the reported averages. The average own-price elasticity is -3.871 for a small store and -3.001 for a large store. The average cross-price elasticity for the same store type is 0.125 for small stores and 0.221 for large stores. These findings indicate that asymmetric competition exists within store types, i.e., the own-price elasticities are larger (in absolute terms) than the cross-price elasticities. Among the cross-price elasticities for the rival store type, the impact of increasing the prices of small stores on the market shares of large stores (0.031) is smaller than that of increasing the prices of large stores on the market shares of small stores (0.221). Cross-price elasticities provide information on which store type gains the most market share if the rival type increases its price by one percent. Small stores gain more than large ones when the price of the rival store type increases. In other words, consumers prefer large stores if prices are sufficiently low to compensate for transportation costs.

Nash-Bertrand equilibrium outcome. Using the demand estimates, we recalculate the Nash price equilibrium and construct price-cost margins, variable profits and the static consumer surplus for each state of the state space. Table 5 presents the summary of these measures for small and large stores. Prices are on average lower in large stores than in small stores. Prices for small stores are lower in liberal markets than in restrictive markets. The average price-cost margin for large stores is approximately 10 percent, which is consistent with previous findings (Aquirregabiria and Vicentini, 2015). Small stores have a smaller average price-cost margin in liberal markets than in restrictive markets, i.e., 8 percent and 10 percent, respectively. The large standard deviation in the price-cost margin for small stores indicates large heterogeneity across markets and the importance of dynamics for market structure and welfare.

Variable profits. Large stores have, on average, about ten times higher variable profits than small stores. The average variable profit across states is also higher in restrictive markets than in liberal markets. The averages of the variable profits for small stores across the generated state space are about SEK 1.20 million in restrictive markets and SEK 1.13 million in liberal markets. For large stores, the corresponding averages are SEK 13.34 million in restrictive markets and SEK 12.56 million in liberal markets.

To evaluate how well our predicted variable profits correspond to stores' actual profits, we compare our profit measures using accounting information on reported profits from Statistics Sweden (SCB). We can obtain a measure of operating profits by subtracting the estimated average fixed cost from the second stage (results are reported in Section 5.3) from our variable profit estimates. 
Overall, our predicted operating profits are good approximations of the annual operating profits reported by SCB.

Static welfare. The total static consumer surplus is higher in markets with a liberal regulation (Table 5). Average static consumer surplus is SEK 21.7 million with a standard deviation of SEK 14.41 million. The corresponding average in restrictive markets is SEK 13.43 million with a standard deviation of SEK 9.2 million. The static producer surplus is substantially higher than the consumer surplus, which suggests that substantial changes in the store mix (dynamics) in a market are needed to obtain a positive welfare change after a policy that decreases producer surplus. Producer surplus is SEK 113.5 million in restrictive markets and SEK 108.6 million in liberal markets.

Asymmetric store type competition. The evolution of the future market structure depends on the static asymmetric store-type competition. Table 6 shows descriptives of the static asymmetric store-type competition based on reduced-form regressions, where variable profits and consumer surplus are simple linear functions of the state variables. The results show a stronger competition effect from an additional store in restrictive than in liberal markets. An additional large store decreases profits by approximately 4 percent for small stores and by approximately 10 percent for large stores. An additional small store decreases profits by approximately 3 percent for small stores and by approximately 1 percent for large stores. We also find that consumer surplus benefits more from an additional large store than from a small store because large stores have lower prices.

\subsection{Structural parameter estimates}

We estimate the entry cost parameters for markets with restrictive and liberal entry regulations. Table 7 presents the parameter estimates for the distributions (in millions of 2001 Swedish kronor) of fixed costs and entry costs for each store type (1 USD=9.39 SEK, $1 \mathrm{EUR}=8.34 \mathrm{SEK})$. The average entry cost for small stores is SEK 10.7 million in restrictive and SEK 11.4 millions in liberal market. For large stores, entry costs are SEK 179.6 million in restrictive and SEK 118.6 million in liberal markets. The estimated average fixed costs are SEK 1.2 million for small and SEK 10.2 million for large stores.

To evaluate the extent to which our average entry cost estimates are reasonable, we compare them to publicly available investment costs for new stores. The reported cost, including land, buildings, and equipment, is 8.5 million for a small Coop store in a small market (Årjäng), 80 million for a large ICA store in a relatively large market (Malmö), and 123 million for the largest ICA store in 
a relatively large market (Västerås). Our estimates of sunk entry costs include other costs such as those related to the regulatory process and, therefore, are larger than the accounting costs. Nevertheless, the range of our cost estimates appears empirically reasonable when assessing the magnitude of our implied value functions.

Table 8 presents a summary of the model prediction of the market structure using observed states in the data in 2001 as starting values for simulation. The simulated model does a good prediction for the number of large stores in all types of markets. The average prediction of the number of small stores is 1-2 more stores than in the observed data, but given the complexity of the market and large heterogeneity across observed markets, the estimated model does a good job in explaining the number of stores in the data. Most importantly, the results show that the model accurately predicts the shares of small/large stores (e.g., share small: 0.70 (data) vs 0.69 (model).

Welfare under the current regulation. Under the current regulation (our base case), welfare is higher in liberal than in restrictive markets with averages of SEK 1,350 million (liberal) and SEK 538 million (restrictive). Producer surplus is on average about four times larger than consumer surplus. Average consumer surplus is SEK 193 million in liberal markets and SEK 99 million in restrictive markets. The corresponding averages for producer surplus is SEK 1,141 million in liberal and SEK 429 million in restrictive markets.

Computing the Markov Perfect Equilibrium. To compute counterfactuals, we need to recalculate the Markov perfect equilibrium, i.e. $\left(V C_{z}, V E_{z}, p_{z}^{e}\right)$, where $p_{z}^{e}$ is the probability of entry with store type $z$. When changing the cost parameters, we need to recalculate transition matrices for incumbents and entrants of each store type in markets with different regulations (Pakes et al., 2007). We assume that the potential entrants for small and large stores follow a Poisson distribution. ${ }^{28}$ The equilibrium solves the system of equations (2), (4), and (5)-(6). The computation algorithm is as follows. Step 0: start with an initial probability to enter for each state, $\mathbf{p}_{z, 0}^{e}$; Step 1: recalculate

\footnotetext{
${ }^{28}$ There are alternatives to implement the Poisson distribution for potential entrants in our dynamic setting. In the end, these methods choose the means of the distributions that fit the observed data. First, we can treat the pool of potential entrants as infinite and model entry as proposed in Wientraub et al. (2008) and Dunne et al. (2013), which implies the estimation of the mean of the Poisson variable that depends on the state $\left(n_{z}, \mathbf{n}_{-z}, \mathbf{y}\right)$ (see Hausman et al. (1984)). It might be unreasonable, however, to assume that there is an infinite (or very large) number of potential entrants in the retail food industry, where the number of stores decreases over time and demand is local. The second alternative is to choose the parameters of these Poisson distributions to fit observed data by simulating the model with estimated cost parameters. For example, using the mean of Poisson distribution equal to 9 for both small and large stores fits the Swedish data well. Another option for the mean of the Poisson distribution is to use the highest number of PBL applications (which is lower than 9) for retail food in one year-market as the mean of the distribution. However, our repeated simulations show that increasing the number of the potential entrants does not affect the quality of the results, but it is more computationally intensive (a large number of combinations is required to compute the value of an element in the transition matrices).
} 
transition probabilities, and use them to update $V C_{z}^{0}$ and $V E_{z}^{0}$; Step 2: update $\mathbf{p}_{z, 1}^{e}$ using $V C_{z}^{0}$ and $V E_{z}^{0}$; Step 3: if $\left\|\mathbf{p}_{z, 1}^{e}-\mathbf{p}_{z, 0}^{e}\right\|<$ error, then stop; otherwise, go to Step $1 .^{29}$

\section{Counterfactual policy experiments}

The estimated parameters of the model are used to evaluate different counterfactual policy experiments, for which we compare outcomes like welfare measures, long-run profits and market structure to the current regulation.

Various policies can be applied to the existing policies to protect small stores from competition from large stores. We examine policy regimes that resemble commonly and recently debated aspects of entry regulations in both the US and Europe. In addition, we exploit heterogeneity across store size and local markets both in the design of the policy and the outcomes. The proposed policy regimes mimic realistic policies that regulators can easily assess, which simplifies the practical implementation.

Two sets of policy experiments are evaluated. We consider policies that aim to protect small incumbents by imposing licensing fees and higher entry costs for large stores (Table 9) (Mankiw and Whinston, 1986; Berry and Waldfogel, 1999). Then, we consider more liberal policies that promote competition by lowering the entry costs for small or large entrants (Table 10).

Our policies primarily target large stores because entry of large stores is one of the most frequently debated questions among retail policy makers in both US and Europe. Large store entrants are the main driver of structural change in the last few decades, e.g., Walmart, Carrefour, Metro, Schwartz, and Tesco. In contrast to the existing literature, which assesses how large stores influence, for instance, prices, employment and productivity, we emphasize welfare (Basker, 2015; Haltiwanger et al., 2010; Maican and Orth, 2015a). Entry of large big-box stores is explicitly regulated in some countries. The regulation in the UK, for instance, explicitly regulates the entry of large stores in out-of-center locations with sales space above 2,500 square meters. ${ }^{30}$ Large stores are expected to influence market structure, profitability, and, thus, the planning process substantially. They also represent the majority of total sales but for a minor share of the number of stores.

Each policy experiment is compared to the current regulation, which is our base case. To summarize the counterfactual results, we focus on the observed market configurations in the data and

\footnotetext{
${ }^{29}$ One way to avoid multiple equilibria is to use different starting values.

${ }^{30}$ The policy in the UK was implemented in 1996.
} 
present the average changes in the long-run profit $\left(V C_{z}\right.$ and $\left.V E_{z}\right)$, entry and exit probabilities ( $p^{x}$ and $p^{e}$ ), discounted consumer and producer surplus, and total welfare (Section 4.4). ${ }^{31}$ We discuss the changes due to each policy in markets with different degrees of regulation (restrictive and liberal) and size (small, medium, and big). After a policy change, we recalculate the new equilibrium as described in Section 5.2 and quantify the changes in these measures at the market configuration (i.e., state). For each variable, we show the mean and standard deviation, which provides information about the direction of the change and heterogeneity of the policy impact across markets. To evaluate the overall changes at the industry level, we show the aggregate changes in welfare in the industry by summing over the changes in each local market.

\subsection{Protecting small incumbents by regulating large stores}

The first set of policies contain three experiments that are easy to compare because they are equivalent in monetary terms for the government. Table 9 summarizes the results.

\subsubsection{Licensing fees for large stores in all markets}

First, we implement a licensing fee for large stores by taxing their variable profits by 5 percent in all markets $\left(C F_{1}\right.$ in Table 9$)$. The aim of this policy is to protect small incumbents. The direct effect of this policy is on the long-run profits $(V C)$. Profits and continuation values of large stores decrease under a licensing fee policy. Stronger competition among large incumbents increases the probability to exit for large stores. It also becomes less attractive to enter as shown by a lower probability to enter for large stores.

Because large stores compete intensely with other large stores than with small stores and because more large incumbents exit, the continuation of small stores and entry values increase. Small stores are less likely to exit and more likely to enter after a licensing fee is imposed for large stores.

The change in welfare depends on the sum of small stores' and large stores' continuation values and the new market configurations of small and large stores. The licensing fee decreases average discounted producer surplus, i.e., the reduction in long-run profits for large stores outweighs the increase in long-run profits for small stores. Discounted consumer surplus increases as a result of changes in the store-type mix available for consumers, i.e., on average, by SEK 24.7 million in restrictive and SEK 63.7 million in liberal markets. In addition, on average, the licensing fee

\footnotetext{
${ }^{31}$ The value functions and welfare measures are in millions of 2001 SEK.
} 
generates revenues to local governments of SEK 15 million in restrictive markets and SEK 60 million in liberal markets.

In sum, total welfare decreases after a licensing fee is imposed for large stores because producer surplus decreases considerably as the licensing fee is paid by all large stores. Welfare decreases more in restrictive markets (SEK -46.4 millions) than in liberal markets (SEK -20.4 millions). The gains to consumers are not enough to compensate for the loss in stores' long-run profits. This is particularly clear in local markets that already have a restrictive entry regulation.

\subsubsection{Licensing fees for large stores in big cities only}

An alternative implementation of the licensing fee is to apply it only in big markets (cities) $\left(C F_{2}\right.$ in Table 9). In this case, a licensing fee that provides the same total revenues to the government as the 5 percent tax of large stores in all markets is a 7.1 percent tax on large stores in big cities only. ${ }^{32}$ The goal of this policy is to protect small stores in big markets where more consumers shop and do not need to travel long distances to buy food.

The long-run profits of large incumbents decrease by on average SEK 8.8 million and SEK 12.1 million in restrictive and liberal markets, respectively. The increasing competition among large stores increases the exit of large stores and induces a profit reallocation to small stores, which become less likely to exit.

Consumer surplus increases, and the increase is higher in liberal markets. In restrictive markets, on average, a licensing fee in big cities only results in a higher increase in consumer surplus than does a licensing fee in all markets (i.e., SEK 31.7 million in $C F_{2}$ vs SEK 24.7 million in $C F_{1}$ ). The producer surplus decreases by on average SEK 9 million in restrictive markets and by SEK 19.3 million in liberal markets. The total change in welfare is negative due to the drop in producer surplus. The overall outcome of policy $C F_{2}$ is a small drop in total welfare, especially in restrictive markets (SEK -9 million in $C F_{2}$ vs SEK -46 million in $C F_{1}$ ).

\subsubsection{Higher entry costs for large stores}

The third experiment increases the entry costs of large stores and protects small stores in the form of lower competitive pressure from large entrants $\left(C F_{3}\right.$ in Table 9$)$. This policy mimics a more

\footnotetext{
${ }^{32}$ Big cities are defined based on our sample of markets for which we exclude the metropolitan areas Stockholm, Göteborg and Malmö.
} 
strict regulation of entry of large big-box stores, which is frequently debated among policymakers, e.g., Walmart's expansion in the US, hypermarket entrants in Europe, and especially the explicit restriction of large entrants in the UK. We implement this policy such that the total increase in entry costs is the same as the government's total tax revenues under the licensing fee policies $\left(C F_{1}\right.$ and $C F_{2}$ ). This corresponds to an increase in entry costs of large stores by SEK 1 million. We assume that there is no additional cost for local governments to be stricter against large stores.

This policy results in fewer entrants, saves fixed and sunk costs, reduces business-stealing, and increases profits. Long-run profits for large stores increase and fewer large stores exit. Store values for small stores increase, and they become less likely to exit. However, less intense competition from fewer large entrants might increase prices and decrease quality and variety available to consumers. The total welfare change is an empirical question in markets with differentiated products.

There are important differences in the mechanisms for how a licensing fee imposed on large stores and an increase in entry cost for large stores influence market structure and profitability for incumbents and entrants. By imposing a licensing fee on variable profits, large stores are worse off. Small incumbents are protected, and their continuation values increase. As a consequence, there is less exit of small stores, and consumers benefit from the new store-type mix. Similar to licensing fee policies on large stores, higher entry costs for large stores lower competition that small stores experience from large. Contrary to licensing fee policies, higher entry costs for large stores decrease competition between large stores, i.e., a lower probability to enter and exit for large stores in both liberal and restrictive markets (Table 9). Lower competition between large stores results in an average increase in long-run profits for large stores by SEK 0.5 million in restrictive markets and by SEK 3.2 million in liberal markets.

Consumer surplus increases and producer surplus decreases, although the magnitudes are lower than under the licensing fee policy. Average producer surplus decreases by SEK 13.9 million in restrictive markets and by SEK 25.6 million in liberal markets. Benefits to consumers are in the form of new store-type configurations and lower concentration, and small stores are more likely to survive and stay in operation. The total welfare change is negative in restrictive markets (i.e., SEK -8.4 million) and positive but small in liberal markets (i.e., SEK 7.2 million). We conclude that from a welfare point of view, an even more restrictive entry regulation in markets that already face strict regulation should be avoided. 


\subsection{More liberal entry policies}

In the second set of policies, we consider two more liberal policies that encourage the entry of small or large stores. We emphasize the role of asymmetric competition from large stores experienced by small stores from the static results, when the entry costs of one store type decreases. First, we increase the number of small stores by decreasing the entry cost of small stores by 15 percent $\left(C F_{4}\right)$. Second, we decrease the entry cost for large stores $\left(C F_{5}\right)$ such that the total entry cost reduction is the same as in $C F_{4}$. A policy that encourages entry of one store type can be advantageous for the other type when there is asymmetric competition between different store types over time. As before, we assume that there are no additional costs for local governments to allow more small or large stores to enter. Table 10 presents the results.

\subsubsection{Lower entry cost for small stores}

The direct effect of lower entry costs for small stores is an increase in the probability to enter and lower entry- and continuation values for small stores (Table 10). In liberal markets, the long-run profits for small stores decrease by SEK 0.13 million, and more small stores exit. Long-run profits for large stores also decrease. Although there is an increase in turnover for large stores, i.e., more entry and exit, most large stores survive and continue to operate. In restrictive markets, there is a net exit of large stores and a reallocation of profits to small stores.

The net effect of encouraging small store entry is an increase in the discounted consumer surplus of on average SEK 30.9 million in restrictive markets and SEK 71.4 million in liberal markets. This comes from that consumers access more small stores and large incumbents still continue to operate. Because small entrants do not compete fiercely with large incumbents, the loss in producer surplus is lower than under the policy regimes that target large stores to protect small incumbents $\left(C F_{1}-C F_{3}\right)$. Total welfare increases in both restrictive (by SEK 36.2 million) and liberal (by SEK 91.1 million) markets.

\subsubsection{Lower entry cost for large stores}

The fifth experiment decreases entry costs of large stores. Table 10 shows that more entry by large stores intensifies competition and reduces the long-run profits for small and large entrants and incumbents (Dunne et al., 2013). The magnitudes of the reductions in store values depend on the degree of asymmetric competition between store types. Long-run profits for large incumbents 
decrease by SEK 3-4 million, on average. For large entrants, the long-run profits decrease more in liberal than in restrictive markets (SEK 2 vs 10 millions). Long-run profits for small incumbents decrease by SEK 0.23 million in liberal markets and by SEK 0.02 million in restrictive markets. Because of more intense competition, both more small stores and large stores exit.

As the continuation values of both large and small incumbents decrease, we observe a reduction in producer surplus. Consumer surplus increases, primarily due to the fact that more large stores operate in the market. Strong competition from new large stores implies lower prices and better quality and variety. The increase in consumer surplus off-sets the reduction in producer surplus and total welfare increases. However, the welfare increase is slightly smaller than in the case of policy that promotes entry of small stores $\left(C F_{4}\right)$. This difference might be attributable to the fact that producer surplus decreases more when entry of large stores is encouraged through asymmetric competition, where large stores decrease small stores' entry- and continuation values more than vice versa.

Dynamics. The dynamic implications captured in the counterfactual policy experiments cannot be summarized by a static model. The reallocation of market shares in favor of small stores can be obtained not only from constraining entry of large stores or taxing large incumbents but also from more entry of large stores where they compete intensely with large incumbent stores. Our findings show that it is crucial to use a dynamic model to capture the patterns of entry, exit and reallocation of profits and to correctly evaluate market outcomes and welfare from alternative policy environments.

\subsection{Heterogeneity across local markets}

As a result of the policy changes, there are substantial differences across states in the changes in welfare measures because of the changes in continuation values, entry values, and probabilities of entering and exiting. There are also differences among states and market size and among restrictive or liberal markets. To highlight heterogeneity across local markets, Table 11 shows differences in consumer surplus, producer surplus and welfare across three market sizes (small, medium, big).

Higher entry costs for large stores $\left(C F_{3}\right)$ implies welfare improvements in small and medium markets. In the case of both restrictive and liberal markets, welfare decreases in large markets. In smaller markets, the benefits to consumers outweigh the losses for stores when entry is restricted. In larger markets, there is enough demand such that consumer surplus does not increase to the extent 
that the overall effect on welfare is positive.

An increase in the entry cost for large stores $\left(C F_{3}\right)$ improves welfare more than a licensing fee policy for large stores in large markets $\left(C F_{2}\right)$ in small markets. The differences are driven by larger losses in producer surplus under the licensing fee. Small markets are affected by the policies imposed in large markets because there are changes in entry and exit strategies in small markets to compensate for the losses in large markets.

Welfare improvements from more liberal entry policies are driven by medium and large markets. A more liberal policy toward the entry of small stores $\left(C F_{4}\right)$ creates larger welfare improvements than does a policy that encourages entry by large stores $\left(C F_{5}\right)$ in medium and large markets. The competition between large stores can bring welfare improvements in small markets because it induces reallocation of market shares from small to large stores and increases product differentiation. High demand prompts more small stores to enter medium and large markets. Small stores can operate effectively in larger markets that are densely populated. Consumers then benefit from lower prices and better quality and variety from more small stores.

In summary, the heterogeneity across markets shows that the gain in total welfare comes from medium and large markets. Fewer individuals are affected per market, demand is limited and our policies do not imply substantial changes in market structure or profitability in small markets.

\section{Robustness analysis}

In this section, we discuss the robustness of our main results. Our main findings are not affected by alternative measures of regulation and profits, different demand and profit function specifications, or changes in the number of potential entrants. Finally, we also highlight possible extensions of the dynamic model.

Regulation measures. We perform the following robustness checks of our regulation measures. First, we present cost estimates using different weights of the variables included in the index. Second, we show cost estimates using the share of non-socialist seats as a measure of the stringency of regulation (online Appendix H). Liberal markets are defined as those with a non-socialist majority in local governments, whereas restrictive markets are those with a socialist majority. Importantly, our empirical findings and welfare results are robust to a number of alternative regulation measures, including different definitions and cut-off points of the regulation index. 
Alternative profit measures. Constructing profits using a discrete choice demand model provides the advantage of improved control for heterogeneity at the store level. A second alternative to construct the variable profits for the states we do not observe in the data is to estimate the profit generating function as a simple additive linear specification in the number of small stores, the number of large stores, and the observed and unobserved market characteristics (Dunne et al., 2013). Then, using the estimates of the profit generating function, we predict the variable profits for the states we do not observe in the data. Although we cannot compute the consumer surplus with this alternative, we evaluate whether the estimated entry and fixed costs are reasonable. Our results that entry costs are higher in restrictive markets remain robust when using this specification (Maican and Orth, 2013).

Number of potential entrants. To re-compute the new transition probabilities in the counterfactual policy experiments, we require the number of potential entrants of each store type (Section 5.2). The new transition probabilities for incumbents and entrants are computed using the structural formulas in POB (pp. 383). Because we employ two different GMM estimators and empirical transition probabilities that use the difference between observed and predicted entry and exit rates from the model, we do not need to have the number of potential entrants when estimating fixed and entry costs. ${ }^{33}$ As discussed in Section 5.2, we checked and confirm the robustness of our counterfactuals with respect to the Poisson distribution specification for the potential entrants using extensive simulations with different values for the mean of the distribution.

Assuming a fixed number of potential entrants from an internal or external pool may be overly restrictive for retailing because it is difficult to define an external pool, and the internal pool is sensitive to changes in local conditions and store type combinations. To relax these restrictions, we assume that the number of potential entrants of each store type comes from a Poisson distribution and that the mean of this distribution is not influenced by changes in the degree of regulation.

A proper model of the endogeneity of potential entrants with respect to regulation is left to future research because it substantially complicates the modeling framework and computations and requires additional assumptions. Changes in regulation might affect entry by changing the number of potential entrants. We do not believe that this is as pronounced in our application to the Swedish retail food market as in many other industries for at least two reasons. First, there was no structural shift in regulation during the study period. Second, we observe multiple entries of large stores in

\footnotetext{
${ }^{33}$ However, the use of a pseudo-log-likelihood estimator requires knowing the number of potential entrants (see pp. 386 in $\mathrm{POB})$.
} 
local markets in two or more consecutive years in the data. Based on discussion with market participants and given that the number of stores decreases over time, it is unreasonable to assume that there are an infinite (or very large) number of potential entrants in the Swedish retail food industry. We observe a constant trend toward larger but fewer stores over time, and the aggregate demand for food products is not likely to change drastically over time.

Demand specification. In the demand analysis, we consider a product basket that contains 11 products (online Appendix B). Our main results are robust to using a small product basket with only three products. The results solely indicate changes in the size of profits and costs; however the cost ratio for small and large stores remains the same. The profit estimates are robust to the method for constructing the market shares used in the demand estimation, i.e., if we use sales instead of quantify (Section 4.1). The demand estimates using market shares based on sales are available from the authors upon request.

In the main specification, we use a large basket for both store types and controls for sales space, which allows us to compare the prices across store types for the same basket. Large stores offer more products than small stores, and it may be important to allow for the different baskets for small and large stores. Our main results remain robust when using different product baskets for store types (online Appendix G). Using small basket for small stores and large basket for large stores, we find somewhat smaller price and cross and own price elasticities. However, the static findings that drive the dynamics mechanisms remain robust, i.e., (i) the consumer surplus is lower than the producer surplus; and (ii) the consumer surplus is larger in liberal markets. Because the quality of the results does not change, we focus on the estimation that use the same basket for both store types.

In addition to the cost shifters, for robustness, the paper also uses additional instruments to identify the price coefficient: (i) the average prices of stores of the same type in other local markets (Hausman, 1997; Nevo, 2001; Hendel and Nevo, 2006); (ii) sum of the sales space of other stores with the same owner and the sum of the sales space of other stores of the same type but with a different owner (BLP instruments) (Berry et al., 1995). Our main findings are robust to the use of these additional instruments. It is important to note that using these instruments requires us to make additional assumptions. The average price in other markets is a valid instrument when there are no national demand shocks. The advantages and disadvantages of different types of instruments in identifying the demand equation are discussed in detail in Nevo (2000).

Cost estimates and sell-off values. The model can be used to estimate sell-off values instead 
of fixed costs (online Appendix C). When estimating the sell-off value instead of the fixed cost, our entry costs are closer the one in Table 7. Aguirregabiria and Suzuki (2014) discuss the normalization assumption that is used to estimate entry and exit games and counterfactuals. In the model in Section 3, the normalization assumption that is used for identification is that sell-off value is zero. If we estimate the model using the sell-off value instead of the fixed cost for identification, we assume that fixed costs are zero.

Modeling firm. Because of computational complexity, this paper solely controls for firm/owner in the static component of the model (the discrete choice demand). To investigate whether it is reasonable to abstract from owners, we run reduced-form regressions on owners. We find that the owner dummy variables are not statistically significant in simple probit regressions that explain the probability to enter or exit at the store level (online Appendix I). Although this approach has various disadvantages, it confirms that owners do not play an important role in our model setting. However, using the framework to understand store dynamics on the basis of the firm/owner is straightforward. A simple choice would be to drop the store type differentiation and only model the dynamics of the number of stores that are affiliated with ICA and Coop, for example. For an examination of entry regulation and an application to the Swedish retail food market, modeling store type differentiation is more interesting because it provides information concerning the trade-offs between small and large stores in a market in which all stores are regulated, which is important for both consumers and firms. Spatial differentiation. Based on the descriptive patterns of the market trending toward larger but fewer stores, the current version of the paper presents an implementation that captures differentiation in store type. We capture the net competitive effects across store types given their geographic locations. It is straightforward to extend the model to also include differentiation in both type and location. The major constraints are the dimensionality of the state space and computational complexity.

\section{Conclusions}

This paper examines store dynamics and cost structures in the retail food market using a structural model of demand, entry and exit. The framework, which builds on Pakes et al. (2007), allows for differentiation in store type. We highlight the role of asymmetries between heterogeneous players in industry dynamics, an aspect that is difficult to assess using theory, two-period static entry models 
or dynamic models with the entry and exit of homogeneous stores. We estimate the sunk entry costs and fixed costs for small and large stores in markets with different degrees of regulation to evaluate the role of regulations in determining industry dynamics. Based on the structural estimates, we perform counterfactual simulations to quantify the impact of entry regulations on long-run profits, market structure and welfare.

Using unique data on all retail food stores in Sweden from 2001 to 2008, we find strong competitive effects of large stores and different cost structures for small and large stores. The estimates of own- and cross-price elasticities, short- and long-run profits, and fixed and entry costs show asymmetries between store types. An additional large store decreases static variable profits by 4 percent for small stores and by 10 percent for large stores. Under the current regulation, entry costs for large stores are lower and average welfare is higher in local markets with liberal rather than restrictive regulation. The discounted producer surplus is on average about four times larger than the discounted consumer surplus.

The estimated parameters of the dynamic model are used to perform counterfactual policy experiments that mimic frequently debated regulatory regimes in the US and in Europe. First, to protect small stores by imposing a licensing fee or higher entry costs for large stores is not welfare improving, in particular in markets that already face a restrictive regulation. Second, to promote competition by lowering the entry costs for either small or large entrants is welfare enhancing. Average discounted producer surplus decreases slightly more when promoting entry of large stores rather than small stores, whereas the increase in average discounted consumer surplus is similar. Welfare improvements are primarily driven by medium and large markets and are larger in liberal than in restrictive markets. To accurately evaluate how alternative entry regulation policies affect welfare, it is crucial to account for the fact that changes in the costs of one store type influence entry, exit, and long-run profits of the rival store type.

In future research, the importance of spatial differentiation and ownership in determining the observed differences in cost structure and welfare could be assessed. The effect of labor costs and new technology on market structure dynamics could also be determined. 


\section{References}

Ackerberg, D., L. Benkard, S. Berry, and A. Pakes (2007): "Econometric Tools for Analyzing Market Outcomes," Handbook of Econometrics, 6, 4171-4276.

Aguirregabiria, V., And P. Mira (2007): "Sequential Estimation of Dynamic Discrete Games," Econometrica, 75(1), 1-53.

Aguirregabiria, V., And J. Suzuki (2014): "Identification and counterfactuals in dynamic models of market entry and exit," Quantitative Marketing and Economics, 12, 267-304.

AquirRegabiria, and Vicentini (2015): "Dynamic Spatial Competition between Multi-Store Firms," Forthcoming, Journal of Industrial Economics.

Arcidiacono, P., P. Bayer, J. Blevins, and P. Ellickson (2013): "Estimation of Dynamic Discrete Choice Models in Continuous Time with an Application to Retail Competition," Mimeo, Duke University.

Asplund, M., And R. Friberg (2002): "Food Prices and Market Structure in Sweden," Scandinavian Journal of Economics, 104(4), 547-567.

Bajari, P., L. Benkard, and J. Levin (2007): "Estimating Dynamic Models of Imperfect Competion," Econometrica, 75(5), 1331-1370.

BAsker, E. (2015): "Change at the Checkout: Tracing the Impact of a Process Innovation," Journal of Industrial Economics, 63(2), 339-370.

Basker, E., S. Klimek, and P. Van (2012): "Supersize It: The Growth of Retail Chains and the Rise of the Big-Box Store," Journal of Economics and Management Strategy, 21(3), 541-582.

Benkard, C. (2004): "A Dynamic Analysis of the Market for Widebodied Commercial Aircraft," Review of Economic Studies, 71, 581-611.

Beresteanu, A., P. Ellickson, and S. Misra (2010): "The Dynamics of Retail Oligopoly," Mimeo, University of Rochester.

BerRy, S. (1994): "Estimating Discrete-Choice Models of Product Differentiation," The RAND Journal of Economics, 25(2), 242-262.

Berry, S., J. Levinsohn, and A. Pakes (1995): "Automobile Prices in Market Equilibrium," Econometrica, 63(4), 841-890.

(2004): "Differentiated Products Demand Systems from a Combination of Micro and Macro Data: The New Vehicle Market," Journal of Political Economy, 112(1), 68-104.

BerRy, S., AND P. Reiss (2007): Handbook of Industrial Organization vol. 3, chap. 29 Empirical Models of Entry and Market Structure, pp. 1845-1886. North-Holland Press.

Berry, S., And J. Waldfogel (1999): "Free Entry and Social Inefficiency in Radio Broadcasting," The RAND Journal of Economics, 30(3), 397-420.

Bertrand, M., and F. Kramarz (2002): "Does Entry Regulation Hinder Job Creation? Evidence from the French Retail Industry," Quarterly Journal of Economics, 117(4), 1369-1413.

Boylaud, O., and G. Nicoletti (2001): "Regulatory reform in retail distribution," OECD Working Paper 32. 
Bresnahan, T., and P. Reiss (1987): "Do Entry Conditions Vary Across Markets?," Brookings Papers on Economic Activity, (3), 883-871.

(1991): "Entry and Competition in Concentrated Markets," Journal of Political Economy, 99(5), 977-1009.

Collard-Wexler, A. (2013): "Demand Fluctuations in the Ready-Mix Concrete Industry," Econometrica, 81(3), 1003-1037.

Doraszelski, U., And A. Pakes (2007): Handbook of Industrial Organization,vol. 3, chap. 30 A Framework for Applied Dynamic Analysis in IO, pp. 1887-1966. North-Holland Press.

Dunne, T., S. Klimek, M. Roberts, and Y. Xu (2013): "Entry, Exit and the Determinants of Market Structure," The RAND Journal of Economics, 44(3), 462-487.

Ellickson, P., S. Houghton, and C. Timmins (2013): "Estimating Network Economies in Retail Chains: A Revealed Preference Approach," The RAND Journal of Economics, 44(2), 169-193.

Ericson, R., And A. PAKes (1995): "Markov-Perfect Industry Dynamics: A Framework for Empirical Work," Review of Economic Studies, 62(1), 53-83.

European Commission (2012): "The Economic Impact of Modern Retail on Choice and Innovation in the EU Food Sector," Written Declaration.

European Competition Network (2011): "ECN Brief Extended Issue," ECN Brief 05/2011, European Competition Network.

European Parliament (2008): "On Investigating and Remedying the Abuse of Power by Large Supermarkets Operating in the European Union," Written Declaration 0088, European Parliament.

Fan, Y., And M. XIAO (2015): "Competition and Subsidies in the Deregulated U.S. Local Telephone Industry," the RAND Journal of Economics (forthcoming).

Fowlie, M., M. Reguant, and S. Ryan (2014): "Market-Based Emissions Regulation and Industry Dynamics," Journal of Political Economy (forthcoming).

Gowrisankaran, G., and J. Krainer (2011): "Entry and Pricing in a Differentiated Products Industry: Evidence from the ATM market," RAND Journal of Economics, 42(1), 1-22.

Gowrisankaran, G., and M. Rysman (2012): "Dynamics of Consumer Demand for New Durable Goods," Journal of Political Economy, 120, 1173-1219.

Gowrisankaran, G., and R. Town (1997): "Dynamic Equilibrium in the Hospital Industry," Journal of Economics and Management Strategy, 6(1), 45-74.

Griffith, R., and H. Harmgart (2005): "Retail Productivity," International Review of Retail, Distribution and Consumer Services, 15(3), 281-290.

Grigolon, L., And F. Verboven (2014): "Nested Logit or Random Coefficients Logit? A Comparison of Alternative Discrete Choice Models of Product Differentiation," Review of Economics and Statistics, 96(5), 916-935.

Haltiwanger, J., R. Jarmin, and C. Krizan (2010): "Mom-and-Pop meet Big-Box: Complements or substitutes?," Journal of Urban Economics, 67, 116-134. 
Hausman, J. (1997): The Economics of New Goodschap. Valuation of New Goods Under Perfect and Imperfect Competition, pp. 207-248. University of Chicago Press.

Hausman, J., B. Hall, and Z. Griliches (1984): "Econometric Models for Count Data with an Application to the Patents R\&D Relationship," Econometrica, 52, 909-938.

Hendel, I., And A. Nevo (2006): "Measuring the Implications of Sales and Consumer Inventory Behavior," Econometrica, 74(6), 1637-1673.

Holmes, T. (2011): "The Diffusion of Wal-Mart and Economies of Density," Econometrica, 79(1), 253-302.

Igami, M., And N. YAng (2015): "Unobserved Heterogeneity in Dynamic Games: Cannibalization and Preemptive Entry of Hamburger Chains in Canada," Quantitative Economics (Forthcoming).

JiA, P. (2008): "What Happens when Wal-Mart comes to Town: An Empirical Analysis of the Discount Retailing Industry," Econometrica, 76(6), 1263-1316.

Maican, F. (2010): "Industry Dynamics and Format Repositioning in Retail," Mimeo, Department of Economics, University of Gothenburg.

Maican, F., And M. Orth (2013): "Entry Regulations, Product Differentiation and Determinants of Market Structure," Research Institute of Industrial Economics (IFN) Working Paper No. 984.

(2015a): "A Dynamic Analysis of Entry Regulations and Productivity in Retail Trade," International Journal of Industrial Organization, 40, 67-80.

(2015b): "Productivity Dynamics and the role of "Big-Box" Entrants in retailing," Working Paper, Research Institute of Industrial Economics (IFN).

Mankiw, N. G., And M. D. Whinston (1986): "Free entry and social inefficiency," Rand Journal of Economics, 17(1), 48-58.

Maruyama, S. (2011): "Socially Optimal Subsidies for Entry: The case of Medicare Payments to HMOs," International Economic Review, 62(105-129), 143-205.

Mazzeo, M. (2002): "Product Choice and Oligopoly Market Structure," The RAND Journal of Economics, 33, 221-242.

Nevo, A. (2000): "A Practitioner's Guide to Estimation of Random-Coefficients Logit Models of Demand," Journal of Economics and Management Strategy, 9(4), 513-548.

$69(2), 307-342$.

Nishida, M. (2014): "Estimating a Model of Strategic Network Choice: The Convenience-Store Industry in Okinawa," Marketing Science, 34(1), 20-38.

Orth, M. (2011): "Entry and Spatial Differentiation in Retail Markets," Mimeo, Research Institute of Industrial Economics (IFN), Stockholm.

Otsuy, T., M. Pesendorfer, and Y. Takahashi (2015): "Pooling Data across Markets in Dynamic Markov Games," Mimeo, London School of Economics.

Pakes, A., M. Ostrovsky, and S. Berry (2007): "Simple Estimators for the Parameters of Discrete Dynamic Games (with Entry/Exit Examples)," The RAND Journal of Economics, 38(2), 373-399. 
Pesendorfer, M., And P. Schmidt-Dengler (2008): "Asymptotic Least Squares Estimators for Dynamic Games," Review of Economic Studies, 75(1), 901-928.

Pilat, D. (1997): "Regulation and Performance in the Distribution Sector," OECD Working Papers 180.

Pozzi, A., And F. Schivardi (2015): "Entry Regulation in Retail Markets," Handbook of Retail and Distribution (forthcoming).

RYAN, S. (2012): "The Costs of Environmental Regulation in a Concentrated Industry," Econometrica, 8(3), 1019-1061.

Sadun, R. (2015): "Does Planning Regulation Protect Independent Retailers?," Review of Economics and Statistics (forthcoming).

Scherer, F., And D. Ross (1990): Industrial Market Structure and Economic Performance. Houghton Mifflin Company.

Schivardi, F., and E. Viviano (2011): "Entry Barriers in Retail Trade," Economic Journal, $121(155), 145-170$.

Seim, K. (2006): "An Empirical Model Of Firm Entry with Endogenous Product-Type Choices," The RAND Journal of Economics, 37(3), 619-640.

Suzuki, J. (2013): "Land Use Regulation as a Barrier to Entry: Evidence from the Texas Lodging Industry," International Economic Review, 54(2), 495-523.

Swedish Competition Authority (2001:4): "Kan Kommunerna Pressa Matpriserna? (Can the Municipalities Put Pressure on Prices?)," Technical Report 4, Stockholm.

(2004:2): "Konsumenterna, Matpriserna och Konkurrensen (Consumers, Retail Food Prices, and Competition)," Technical Report 2, Stockholm.

Sweeting, A. (2013): "Dynamic Product Positioning in Differentiated Product Markets: The Effect of Fees for Musical Performance Rights on the Commercial Radio Industry," Econometrica, 81(5), 1763-1803.

TAKAhashi, Y. (2015): "Estimating a War of Attrition: The Case of the US Movie Theater Industry," American Economic Review, 7(105), 2204-2241.

Toivanen, O., and M. Waterson (2011): "Retail Chain Expansion: The Early Years of McDonalds in Great Britain," CEPR Discussion Paper 8534.

Turner, M., A. Haughwout, and W. van der Klaauw (2014): "Land Use Regulation and Welfare," Econometrica, 82(4), 1341-1403.

Wientraub, G., L. Benkard, and B. Van Roy (2008): "Markov Perfect Industry Dynamics with Many Firms," Econometrica, 76(6), 1375-1411. 
Table 1: Characteristics of the Swedish retail food market

\begin{tabular}{|c|c|c|c|c|c|c|c|c|}
\hline \multirow[t]{2}{*}{ Year } & \multicolumn{2}{|c|}{ No. of stores } & \multirow{2}{*}{$\begin{array}{l}\text { No. of } \\
\text { entrants }\end{array}$} & \multirow{2}{*}{$\begin{array}{l}\text { No. of } \\
\text { exits }\end{array}$} & \multicolumn{2}{|c|}{ Sales space $\left(m^{2}\right)$} & \multicolumn{2}{|c|}{ Sales } \\
\hline & total & share large & & & total & share large & total & share large \\
\hline 2001 & 5,240 & 18.2 & & 385 & $2,783,921$ & 0.578 & $155,312,368$ & 0.580 \\
\hline 2002 & 4,926 & 19.3 & 71 & 157 & $2,704,713$ & 0.579 & $158,576,880$ & 0.596 \\
\hline 2003 & 4,882 & 19.6 & 113 & 240 & $2,770,370$ & 0.582 & $167,942,368$ & 0.601 \\
\hline 2004 & 4,770 & 19.8 & 128 & 257 & $2,791,441$ & 0.579 & $172,090,400$ & 0.600 \\
\hline 2005 & 4,680 & 20.0 & 167 & 242 & $2,885,817$ & 0.576 & $175,726,624$ & 0.600 \\
\hline 2006 & 4,564 & 20.5 & 126 & 198 & $2,928,130$ & 0.590 & $181,214,288$ & 0.611 \\
\hline 2007 & 4,489 & 21.3 & 123 & 193 & $2,983,612$ & 0.604 & $188,431,040$ & 0.616 \\
\hline 2008 & 4,398 & 21.7 & 102 & & $3,082,295$ & 0.605 & $193,053,040$ & 0.618 \\
\hline
\end{tabular}

NOTE: DELFI is provided by Delfi Marknadspartner AB and contains all retail food stores based on their geographical location (address). Large stores are defined as the five largest store types in DELFI (hypermarkets, department stores, large supermarkets, large grocery stores, and other stores). Sales (incl. 12\% VAT) are measured in thousands of 2001 SEK (1 USD=9.39 SEK, $1 \mathrm{EUR}=8.34 \mathrm{SEK}$ ).

Table 2: Entry and exit rates across local markets and years

\begin{tabular}{lclccc}
\hline \hline & $\mathrm{p} 10$ & Median & $\mathrm{p} 90$ & mean & sd \\
\hline A. Entry rate & & & & & \\
\hline 2002 & 0 & 0.0 & 0.039 & 0.012 & 0.041 \\
2003 & 0 & 0.0 & 0.071 & 0.019 & 0.045 \\
2004 & 0 & 0.0 & 0.091 & 0.031 & 0.031 \\
2005 & 0 & 0.0 & 0.125 & 0.040 & 0.073 \\
2006 & 0 & 0.0 & 0.083 & 0.021 & 0.047 \\
2007 & 0 & 0.0 & 0.095 & 0.027 & 0.065 \\
\hline B. Exit rate & & & & & \\
\hline 2002 & 0 & 0.062 & 0.182 & 0.073 & 0.083 \\
2003 & 0 & 0.0 & 0.286 & 0.033 & 0.053 \\
2004 & 0 & 0.0 & 0.333 & 0.050 & 0.050 \\
2005 & 0 & 0.0 & 0.156 & 0.054 & 0.073 \\
2006 & 0 & 0.0 & 0.153 & 0.055 & 0.078 \\
2007 & 0 & 0.0 & 0.143 & 0.046 & 0.075 \\
\hline NOTE: Thi
\end{tabular}

NOTE: This table shows descriptive statistics of entry and exit rates across municipalities.

Table 3: Estimated parameters of the demand equation: Nested logit

\begin{tabular}{|c|c|c|c|c|c|c|c|c|}
\hline & \multicolumn{2}{|c|}{ OLS } & \multicolumn{2}{|c|}{ 2SLS } & \multicolumn{2}{|c|}{ OLS } & \multicolumn{2}{|c|}{ 2SLS } \\
\hline & Coef. & Std. & Coef. & Std. & Coef. & Std. & Coef. & Std. \\
\hline $\log$ of space $\left(m^{2}\right)$ & 0.016 & 0.003 & 0.021 & 0.003 & 0.282 & 0.002 & 0.401 & 0.132 \\
\hline Log of income & & & & & -1.106 & 0.006 & 1.298 & 0.300 \\
\hline Log of income squared & & & & & 0.055 & 0.0004 & -0.110 & 0.010 \\
\hline $\mathrm{ICA}$ & 0.129 & 0.010 & 0.152 & 0.012 & 0.094 & 0.007 & 1.881 & 0.234 \\
\hline Axfood & 0.136 & 0.010 & 0.150 & 0.011 & 0.045 & 0.007 & 1.624 & 0.129 \\
\hline Coop & 0.218 & 0.011 & 0.241 & 0.013 & 0.086 & 0.008 & 1.806 & 0.223 \\
\hline Bergendahls & -0.061 & 0.020 & -0.047 & 0.020 & -0.121 & 0.014 & 1.266 & 0.215 \\
\hline Price & 0.016 & 0.0001 & 0.017 & 0.0002 & 0.0006 & 0.0001 & 0.019 & 0.004 \\
\hline Market share (grp) & 0.971 & 0.0015 & 0.959 & 0.0040 & 0.898 & 0.0014 & 0.637 & 0.169 \\
\hline
\end{tabular}

NOTE: The average price of a type in the other local markets and average wages are used as instruments for prices. The log of the average market share in its own group in the other local markets is used as instrument for market share within the group. 
Table 4: Average estimated own and cross price elasticities by store type

\begin{tabular}{lrrrr}
\hline \hline & Small $(i)$ & Small $(j)$ & Large $(k)$ & Large $(m)$ \\
\hline Small $(i)$ & -3.871 & 0.125 & 0.221 & 0.221 \\
& $(0.423)$ & $(0.138)$ & $(0.051)$ & $(0.051)$ \\
Small $(j)$ & 0.125 & -3.871 & 0.221 & 0.221 \\
& $(0.138)$ & $(0.423)$ & $(0.051)$ & $(0.051)$ \\
Large $(k)$ & 0.031 & 0.031 & -3.001 & 0.841 \\
& $(0.007)$ & $(0.007)$ & $(0.629)$ & $(0.466)$ \\
Large $(m)$ & 0.031 & 0.031 & 0.841 & -3.001 \\
& $(0.007)$ & $(0.007)$ & $(0.466)$ & $(0.629)$
\end{tabular}

NOTE: Boostraped standard errors are in parentheses. Cell entries $r, c$, where $r$ indexes row and $c$ column, give the percentage change in market share of $r$ with $1 \%$ change in price of $c$.

Table 5: Summary of the Nash-Bertrand equilibrium outcome

\begin{tabular}{|c|c|c|c|c|c|c|}
\hline \multirow[t]{2}{*}{ Market type } & \multicolumn{2}{|c|}{ Price } & \multicolumn{2}{|c|}{ Price-cost margin $(\%)$} & \multirow{2}{*}{$\begin{array}{l}\text { Total } \\
\text { consumer } \\
\text { surplus }\end{array}$} & \multirow{2}{*}{$\begin{array}{l}\text { Total } \\
\text { producer } \\
\text { surplus }\end{array}$} \\
\hline & Small & Large & Small & Large & & \\
\hline Restrictive & $\begin{array}{l}211.4 \\
(4.66)\end{array}$ & $\begin{array}{l}192.01 \\
(4.03)\end{array}$ & $\begin{array}{l}10.28 \\
(1.52)\end{array}$ & $\begin{array}{l}9.77 \\
(0.44)\end{array}$ & $\begin{array}{l}13.43 \\
(9.2)\end{array}$ & $\begin{array}{l}113.50 \\
(56.91)\end{array}$ \\
\hline Liberal & $\begin{array}{l}208.65 \\
(2.14)\end{array}$ & $\begin{array}{l}193.38 \\
(4.76)\end{array}$ & $\begin{array}{l}8.97 \\
(2.59)\end{array}$ & $\begin{array}{l}10.09 \\
(0.69)\end{array}$ & $\begin{array}{l}21.73 \\
(14.41)\end{array}$ & $\begin{array}{l}108.60 \\
(96.49)\end{array}$ \\
\hline
\end{tabular}

NOTE: The figures represent mean and standard deviation (in parentheses) of the equilibrium outcomes of generated state space. Price is in SEK (1 USD=9.39 SEK, 1 EUR=8.34 SEK). Total consumer and producer surplus are in millions SEK.

Table 6: Asymmetric store type competition

\begin{tabular}{|c|c|c|c|c|}
\hline \multirow[t]{2}{*}{$\begin{array}{l}\text { Dependent } \\
\text { variable }\end{array}$} & \multicolumn{2}{|c|}{$\begin{array}{l}\text { Log of variable profits } \\
\text { in restrictive markets }\end{array}$} & \multicolumn{2}{|c|}{$\begin{array}{l}\text { Log of variable profits } \\
\text { in liberal markets }\end{array}$} \\
\hline & $\begin{array}{l}\text { Small } \\
\text { store }\end{array}$ & $\begin{array}{l}\text { Large } \\
\text { store }\end{array}$ & $\begin{array}{l}\text { Small } \\
\text { store }\end{array}$ & $\begin{array}{l}\text { Large } \\
\text { store }\end{array}$ \\
\hline Number of small & $\begin{array}{c}-0.0374 \\
(0.0003)\end{array}$ & $\begin{array}{l}-0.0045 \\
(0.0002)\end{array}$ & $\begin{array}{l}-0.0330 \\
(0.0002)\end{array}$ & $\begin{array}{l}-0.0032 \\
(0.0001)\end{array}$ \\
\hline Number of large & $\begin{array}{l}-0.0412 \\
(0.0012)\end{array}$ & $\begin{array}{l}-0.1336 \\
(0.0007)\end{array}$ & $\begin{array}{l}-0.0358 \\
(0.0007)\end{array}$ & $\begin{array}{l}-0.1076 \\
(0.0005)\end{array}$ \\
\hline Market fixed effects & Yes & Yes & Yes & Yes \\
\hline$R^{2}$ & 0.974 & 0.996 & 0.971 & 0.995 \\
\hline
\end{tabular}


Table 7: Estimation results for structural parameters

\begin{tabular}{lcc}
\hline \hline & Small stores & Large stores \\
\hline Entry cost restrictive markets & $\begin{array}{c}10.700 \\
(1.191)\end{array}$ & $\begin{array}{c}179.625 \\
(25.275)\end{array}$ \\
& 11.416 & 118.618 \\
& $(1.431)$ & $(16.394)$ \\
Entry cost liberal markets & 1.219 & 10.274 \\
& $(0.293)$ & $(2.001)$ \\
Fixed cost & & \\
& NOTE: Bootstrapped standard errors are presented in paren- \\
theses. Large stores are defined as the five largest store types \\
in DELFI (hypermarkets, department stores, large supermar- \\
kets, large grocery stores, and other stores). Municipalities \\
are defined as having restrictive (liberal) regulations if the \\
regulation index, defined in Section 2, is below (above) the \\
median. Fixed cost follows an exponential distribution. The \\
entry costs for small and large stores ( $\kappa_{\text {small }}$ and $k_{\text {large }}$ ) fol- \\
low a unimodal distribution with parameters $a_{1}$ and $a_{2}$.
\end{tabular}

Table 8: Comparison between observed data and model prediction

\begin{tabular}{|c|c|c|c|c|}
\hline & \multicolumn{2}{|c|}{ Restrictive markets } & \multicolumn{2}{|c|}{ Liberal markets } \\
\hline & Data & Model & Data & Model \\
\hline \multicolumn{5}{|l|}{ Small Markets } \\
\hline Number of small stores & 12.650 & 15.493 & 11.634 & 13.103 \\
\hline Number of large stores & 4.467 & 6.665 & 4.518 & 5.698 \\
\hline Share of small stores & 0.702 & 0.698 & 0.682 & 0.678 \\
\hline Share of large stores & 0.298 & 0.302 & 0.318 & 0.322 \\
\hline \multicolumn{5}{|l|}{ Medium Markets } \\
\hline Number of small stores & 12.206 & 14.784 & 12.880 & 14.867 \\
\hline Number of large stores & 4.454 & 5.338 & 5.559 & 6.528 \\
\hline Share of small stores & 0.709 & 0.689 & 0.680 & 0.670 \\
\hline Share of large stores & 0.291 & 0.311 & 0.320 & 0.330 \\
\hline \multicolumn{5}{|l|}{ Large Markets } \\
\hline Number of small stores & 22.731 & 25.459 & 23.855 & 25.990 \\
\hline Number of large stores & 7.189 & 8.194 & 8.780 & 10.480 \\
\hline Share of small stores & 0.744 & 0.745 & 0.716 & 0.656 \\
\hline Share of large stores & 0.256 & 0.254 & 0.284 & 0.344 \\
\hline
\end{tabular}

NOTE: The figures represent the mean values across observed states

(2001-2008) and the simulated model states beginning from 2001. 
Table 9: Policy experiments: Changes in market structure and welfare due to licensing fees and increase in entry cost for large stores

\begin{tabular}{|c|c|c|c|c|c|c|}
\hline & \multicolumn{2}{|c|}{$\begin{array}{c}C F_{1}: \text { Licensing fee for } \\
\text { large in all markets }\end{array}$} & \multicolumn{2}{|c|}{$\begin{array}{c}C F_{2}: \text { Licensing fee for } \\
\text { large in big markets }\end{array}$} & \multicolumn{2}{|c|}{$\begin{array}{c}C F_{3}: \text { Increase in entry } \\
\text { cost for large }\end{array}$} \\
\hline & Restrictive & Liberal & Restrictive & Liberal & Restrictive & Liberal \\
\hline \multicolumn{7}{|c|}{ Panel A: Small stores } \\
\hline \multicolumn{7}{|c|}{ Long-run incumbents' profit $(V C)$} \\
\hline Mean & 0.10 & 0.12 & 0.36 & 0.11 & 0.36 & 0.21 \\
\hline Std. & 0.22 & 0.45 & 0.60 & 0.44 & 0.60 & 0.74 \\
\hline \multicolumn{7}{|l|}{ Probablility to exit $\left(p^{x}\right)$} \\
\hline Mean & -0.005 & -0.020 & -0.019 & -0.017 & -0.019 & -0.027 \\
\hline Std. & 0.008 & 0.053 & 0.017 & 0.048 & 0.017 & 0.061 \\
\hline \multicolumn{7}{|c|}{ Long-run entrants' profit $(V E)$} \\
\hline Mean & 0.12 & 0.02 & 0.19 & 0.06 & 0.23 & 0.13 \\
\hline Std. & 0.27 & 0.14 & 0.31 & 0.21 & 0.34 & 0.75 \\
\hline \multicolumn{7}{|l|}{ Probability to enter $\left(p^{e}\right)$} \\
\hline Mean & -0.005 & -0.003 & -0.004 & $-9 e-04$ & -0.003 & -0.001 \\
\hline Std. & 0.018 & 0.015 & 0.050 & 0.018 & 0.042 & 0.018 \\
\hline \multicolumn{7}{|c|}{ Panel B: Large stores } \\
\hline \multicolumn{7}{|c|}{ Long-run incumbents' profit $(V C)$} \\
\hline Mean & -13.73 & -15.83 & -8.83 & -12.13 & 0.47 & 3.21 \\
\hline Std. & 7.78 & 17.30 & 11.02 & 21.28 & 2.72 & 12.31 \\
\hline \multicolumn{7}{|l|}{ Probablility to exit $\left(p^{x}\right)$} \\
\hline Mean & 0.028 & $6 e-04$ & 0.002 & 0.001 & -0.002 & -0.009 \\
\hline Std. & 0.040 & 0.002 & 0.019 & 0.004 & 0.041 & 0.046 \\
\hline \multicolumn{7}{|c|}{ Long-run entrants' profit $(V E)$} \\
\hline Mean & -5.50 & -15.76 & -4.67 & -16.05 & 0.47 & 0.99 \\
\hline Std. & 5.62 & 12.14 & 5.62 & 13.07 & 2.39 & 5.80 \\
\hline \multicolumn{7}{|l|}{ Probability to enter $\left(p^{e}\right)$} \\
\hline Mean & -0.012 & -0.015 & -0.014 & 0.002 & -0.005 & -0.002 \\
\hline Std. & 0.033 & 0.034 & 0.038 & 0.020 & 0.016 & 0.029 \\
\hline \multicolumn{7}{|c|}{ Panel C: Welfare } \\
\hline \multicolumn{7}{|c|}{ Discounted consumer surplus } \\
\hline Mean & 24.72 & 63.75 & 31.79 & 61.05 & 15.23 & 23.53 \\
\hline Std. & 28.85 & 64.44 & 26.03 & 62.52 & 20.31 & 42.66 \\
\hline \multicolumn{7}{|c|}{ Discounted producer surplus } \\
\hline Mean & -75.14 & -86.20 & -34.08 & -83.54 & -13.93 & -25.67 \\
\hline Std. & 63.32 & 94.69 & 74.15 & 130.61 & 30.40 & 68.69 \\
\hline \multicolumn{7}{|l|}{ Welfare } \\
\hline Mean & -46.49 & -20.45 & -9.06 & -19.27 & -8.47 & 7.28 \\
\hline Std. & 72.54 & 128.53 & 59.49 & 164.79 & 56.47 & 88.81 \\
\hline Change at the industry & $-11,575.25$ & $-5,480.02$ & $-2,002.46$ & $-5,163.988$ & $-1,761.69$ & $1,514.14$ \\
\hline
\end{tabular}


Table 10: Policy experiments: Changes in market structure and welfare due to more liberal entry policies

\begin{tabular}{|c|c|c|c|c|}
\hline & \multicolumn{2}{|c|}{$\begin{array}{c}C F_{4}: \text { Lower entry } \\
\text { cost for small }\end{array}$} & \multicolumn{2}{|c|}{$\begin{array}{c}C F_{5}: \text { Lower entry } \\
\text { cost for large }\end{array}$} \\
\hline & Restrictive & Liberal & Restrictive & Liberal \\
\hline \multicolumn{5}{|c|}{ Panel A: Small stores } \\
\hline \multicolumn{5}{|c|}{ Long-run incumbents' profit $(V C)$} \\
\hline Mean & 0.29 & -0.13 & -0.02 & -0.23 \\
\hline Std. & 0.54 & 0.70 & 0.70 & 1.13 \\
\hline \multicolumn{5}{|l|}{ Probablility to exit $\left(p^{x}\right)$} \\
\hline Mean & -0.031 & 0.002 & 0.001 & 0.001 \\
\hline Std. & 0.078 & 0.072 & 0.010 & 0.001 \\
\hline \multicolumn{5}{|c|}{ Long-run entrants' profit $(V E)$} \\
\hline Mean & -0.02 & -0.11 & 0.41 & 0.01 \\
\hline Std. & 0.21 & 0.19 & 0.79 & 0.56 \\
\hline \multicolumn{5}{|l|}{ Probability to enter $\left(p^{e}\right)$} \\
\hline Mean & 0.008 & 0.012 & -0.004 & -0.002 \\
\hline Std. & 0.054 & 0.034 & 0.048 & 0.016 \\
\hline \multicolumn{5}{|c|}{ Panel B: Large stores } \\
\hline \multicolumn{5}{|c|}{ Long-run incumbents' profit $(V C)$} \\
\hline Mean & -3.17 & -3.03 & -4.34 & -3.36 \\
\hline Std. & 2.98 & 7.25 & 3.17 & 5.35 \\
\hline \multicolumn{5}{|l|}{ Probability to exit $\left(p^{x}\right)$} \\
\hline Mean & 0.008 & $9 \mathrm{e}-04$ & 0.002 & $6 e-04$ \\
\hline Std. & 0.017 & 0.010 & 0.011 & 0.008 \\
\hline \multicolumn{5}{|c|}{ Long-run entrants' profit $(V E)$} \\
\hline Mean & -1.42 & -10.30 & -2.00 & -10.33 \\
\hline Std. & 2.09 & 12.63 & 2.50 & 12.38 \\
\hline \multicolumn{5}{|l|}{ Probability to enter $\left(p^{e}\right)$} \\
\hline Mean & $3 e-04$ & 0.002 & $2 \mathrm{e}-04$ & 0.006 \\
\hline Std. & 0.002 & 0.016 & 0.001 & 0.022 \\
\hline \multicolumn{5}{|c|}{ Panel C: Welfare } \\
\hline \multicolumn{5}{|c|}{ Discounted consumer surplus } \\
\hline Mean & 30.91 & 71.45 & 28.81 & 68.68 \\
\hline Std. & 25.33 & 71.41 & 21.85 & 68.99 \\
\hline \multicolumn{5}{|c|}{ Discounted producer surplus } \\
\hline Mean & -6.44 & -2.72 & -14.35 & -7.38 \\
\hline Std. & 26.89 & 45.34 & 30.59 & 40.18 \\
\hline \multicolumn{5}{|l|}{ Welfare } \\
\hline Mean & 36.21 & 91.08 & 27.16 & 82.49 \\
\hline Std. & 34.14 & 84.71 & 33.07 & 77.09 \\
\hline Change at the industry & $8,001.78$ & $21,676.68$ & $19,632.8$ & $6,002.5$ \\
\hline \multicolumn{5}{|c|}{$\begin{array}{l}\text { NOTE: The mean and standard deviation are computed based on the observed states in the } \\
\text { data. Welfare is computed as the sum of the discounted consumer and producer surplus. } V C \text {, } \\
V E \text {, consumer surplus, producer surplus, and welfare are in millions of SEK ( } 1 \text { USD }=9.39 \\
\text { SEK, } 1 \text { EUR }=8.34 \mathrm{SEK} \text { ). The counterfactuals } C F_{4} \text { and } C F_{5} \text { are similar, with respect to the } \\
\text { total sum collected by the government. } C F_{4}-\text { lower entry cost for small stores by } 15 \text { percent; } \\
C F_{5}-\text { lower entry cost for large stores. }\end{array}$} \\
\hline
\end{tabular}


Table 11: Policy experiments: Market size and heterogeneity of welfare changes due to policy modifications

\begin{tabular}{|c|c|c|c|c|c|c|c|c|}
\hline & \multicolumn{2}{|c|}{ All markets } & \multicolumn{2}{|c|}{ Small markets } & \multicolumn{2}{|c|}{ Medium markets } & \multicolumn{2}{|c|}{ Big markets } \\
\hline & Restr. & Lib. & Restr. & Lib. & Restr. & Lib. & Restr. & Lib. \\
\hline \multicolumn{9}{|c|}{$C F_{1}$ : Licensing fee for large stores in all markets } \\
\hline \multicolumn{9}{|c|}{ Discounted consumer surplus } \\
\hline Mean & 24.72 & 63.75 & 21.94 & 24.67 & 24.95 & 98.59 & 26.10 & 59.48 \\
\hline Std. & 28.85 & 64.44 & 0.24 & 0.95 & 29.61 & 63.10 & 35.70 & 66.15 \\
\hline \multicolumn{9}{|c|}{ Discounted producer surplus } \\
\hline Mean & -75.14 & -86.20 & -37.16 & -35.36 & -52.93 & -76.75 & -112.21 & -100.04 \\
\hline Std. & 63.32 & 94.69 & 41.77 & 40.76 & 41.59 & 60.64 & 66.67 & 108.05 \\
\hline \multicolumn{9}{|l|}{ Welfare } \\
\hline Mean & -46.49 & -20.45 & -15.22 & -10.89 & -30.60 & 24.94 & -75.22 & -40.00 \\
\hline Std. & 72.54 & 128.53 & 41.76 & 41.10 & 47.90 & 107.52 & 88.83 & 142.94 \\
\hline Change at the industry & $-11,575.25$ & $-5,480.02$ & -897.99 & -381.15 & $-2,478.24$ & $1,621.35$ & $-8,199.00$ & $-6,720.22$ \\
\hline \multicolumn{9}{|c|}{$C F_{2}$ : Licensing fee for large stores in big markets (equivalent of $C F_{1}$ ) } \\
\hline \multicolumn{9}{|c|}{ Discounted consumer surplus } \\
\hline Mean & 31.79 & 61.05 & 22.13 & 24.72 & 33.14 & 99.10 & 36.01 & 55.15 \\
\hline Std. & 26.03 & 62.52 & 0.29 & 0.97 & 21.45 & 63.46 & 33.83 & 62.54 \\
\hline \multicolumn{9}{|c|}{ Discounted producer surplus } \\
\hline Mean & -34.08 & -83.54 & -5.48 & -17.90 & -9.06 & -20.55 & -70.99 & -120.39 \\
\hline Std. & 74.15 & 130.61 & 10.96 & 37.04 & 36.65 & 55.78 & 98.47 & 147.64 \\
\hline \multicolumn{9}{|l|}{ Welfare } \\
\hline Mean & -9.06 & -19.27 & 16.65 & 6.62 & 8.46 & 77.93 & -41.60 & -62.27 \\
\hline$S t d$. & 59.49 & 164.79 & 11.05 & 37.22 & 33.90 & 87.13 & 78.67 & 185.87 \\
\hline Change at the industry & $-2,002.46$ & $-5,163.98$ & 982.07 & 231.73 & 634.39 & $5,065.36$ & $-3,618.93$ & $-10,461.09$ \\
\hline \multicolumn{9}{|c|}{$C F_{3}$ : Increase in entry cost of large stores (equivalent of $C F_{1}$ ) } \\
\hline \multicolumn{9}{|c|}{ Discounted consumer surplus } \\
\hline Mean & 15.23 & 23.53 & 22.04 & 24.72 & 13.28 & 17.61 & 12.16 & 24.37 \\
\hline Std. & 20.31 & 42.66 & 0.14 & 0.97 & 20.01 & 34.94 & 25.82 & 49.47 \\
\hline \multicolumn{9}{|c|}{ Discounted producer surplus } \\
\hline Mean & -13.93 & -25.67 & -2.42 & -13.45 & -15.36 & -8.55 & -19.03 & -34.75 \\
\hline Std. & 30.40 & 68.69 & 12.38 & 63.46 & 21.32 & 31.91 & 39.76 & 77.96 \\
\hline \multicolumn{9}{|l|}{ Welfare } \\
\hline Mean & -8.47 & 7.28 & 19.20 & 15.26 & -4.59 & 39.94 & -32.27 & -3.16 \\
\hline Std. & 56.47 & 88.81 & 11.69 & 63.91 & 49.83 & 66.09 & 70.55 & 97.26 \\
\hline Change at industry & $-1,761.69$ & $1,514.14$ & $1,113.69$ & 549.50 & -325.74 & $1,397.98$ & $-2,549.64$ & -433.34 \\
\hline$C F_{4}$ : Decrease in entry & ost of small & tores & & & & & & \\
\hline Discounted consumer su & plus & & & & & & & \\
\hline Mean & 30.91 & 71.45 & 22.06 & 24.73 & 35.15 & 98.48 & 32.52 & 72.17 \\
\hline Std. & 25.33 & 71.41 & 0.30 & 0.97 & 25.74 & 63.63 & 30.43 & 77.04 \\
\hline Discounted producer su & lus & & & & & & & \\
\hline Mean & -6.44 & -2.72 & -5.20 & 0.21 & -8.22 & -8.78 & -5.85 & -1.21 \\
\hline Std. & 26.89 & 45.34 & 12.52 & 39.24 & 17.65 & 38.34 & 36.25 & 48.64 \\
\hline Welfare & & & & & & & & \\
\hline Mean & 36.21 & 91.08 & 17.40 & 30.43 & 35.94 & 108.86 & 48.41 & 98.67 \\
\hline Std. & 34.14 & 84.71 & 11.80 & 44.15 & 36.51 & 67.31 & 36.47 & 91.94 \\
\hline Change at the industry & $8,001.78$ & $21,676.68$ & $1,008.94$ & $1,065.15$ & $2,587.48$ & $6,205.08$ & $4,405.35$ & $14,406.44$ \\
\hline$C F_{5}$ : Decrease in entry & ost of large & ores (equiv & $\mathrm{t}$ of $\left.\mathrm{CF}_{4}\right)$ & & & & & \\
\hline Discounted consumer st & plus & & & & & & & \\
\hline Mean & 28.81 & 68.68 & 22.14 & 24.72 & 31.53 & 98.00 & 30.38 & 67.88 \\
\hline Std. & 21.85 & 68.99 & 0.34 & 0.97 & 22.69 & 64.67 & 26.16 & 73.10 \\
\hline Discounted producer su & lus & & & & & & & \\
\hline Mean & -14.35 & -7.38 & -2.49 & 2.39 & -14.90 & -11.15 & -20.27 & -8.08 \\
\hline Std. & 30.59 & 40.18 & 12.28 & 25.33 & 20.75 & 24.92 & 40.17 & 46.17 \\
\hline Welfare & & & & & & & & \\
\hline Mean & 27.16 & 82.49 & 19.66 & 30.63 & 23.54 & 97.21 & 35.11 & 89.47 \\
\hline Std. & 33.07 & 77.09 & 12.15 & 33.93 & 33.50 & 62.01 & 40.07 & 85.11 \\
\hline Change at the industry & $6,002.50$ & $19,632.8$ & $1,159.65$ & $1,102.851$ & $1,718.41$ & $5,735.26$ & $3,124.44$ & $12,794.68$ \\
\hline
\end{tabular}

NOTE: The mean and standard deviation are computed based on the observed states in the data (1 USD=9.39 SEK, 1

$\mathrm{EUR}=8.34 \mathrm{SEK})$. Welfare is computed as the sum of the discounted consumer and producer surplus. 

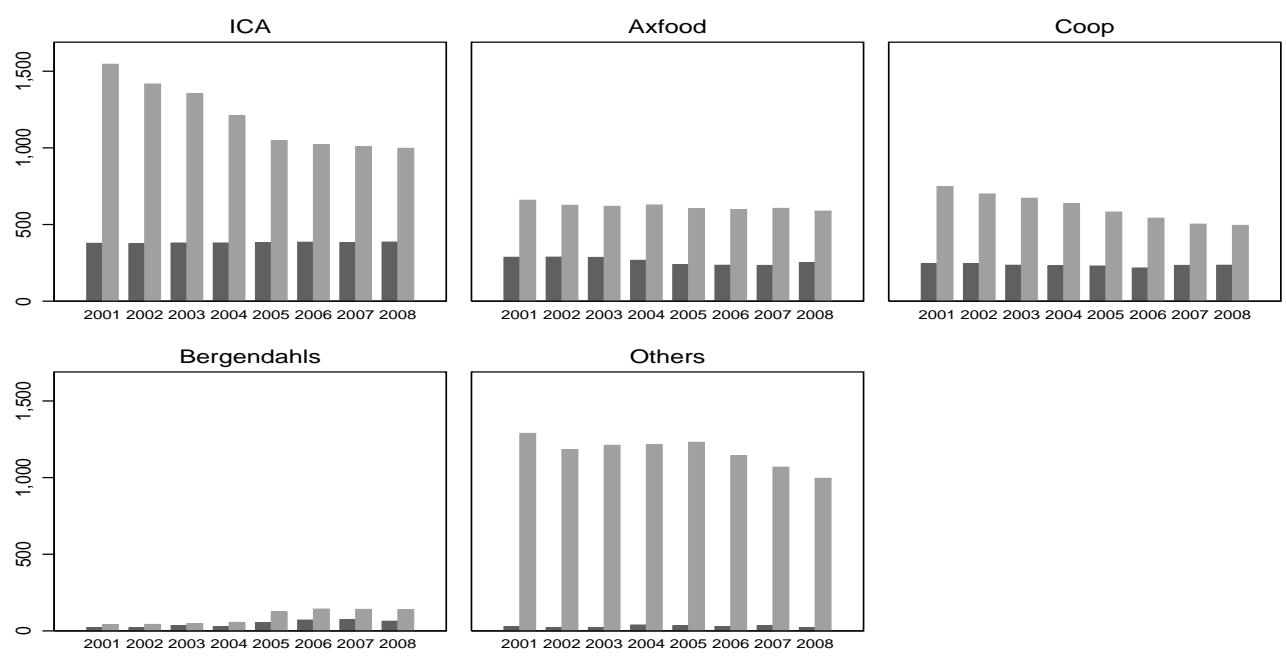

Number of large

Number of small

Figure 1: Number of large and small stores by firm affiliation 2001-2008.

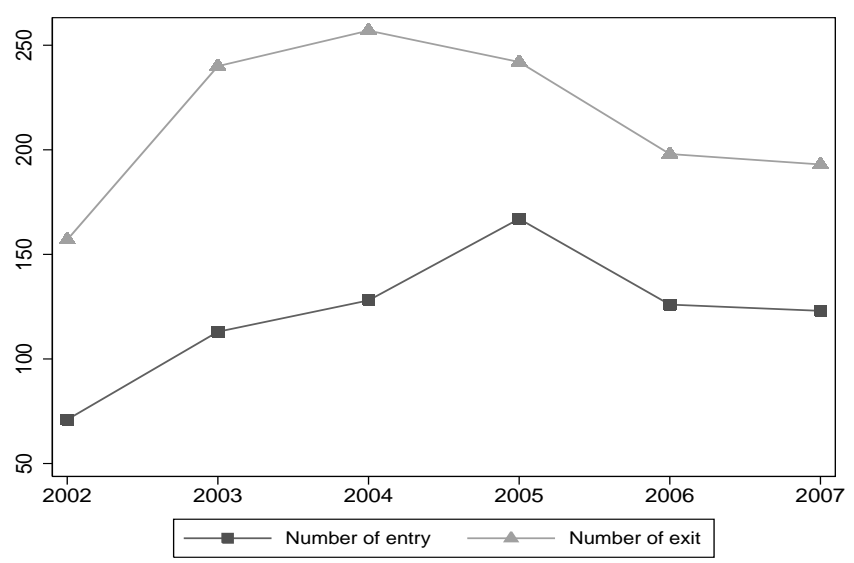

Figure 2: Total number of entries and exits in Sweden 2002-2007. 


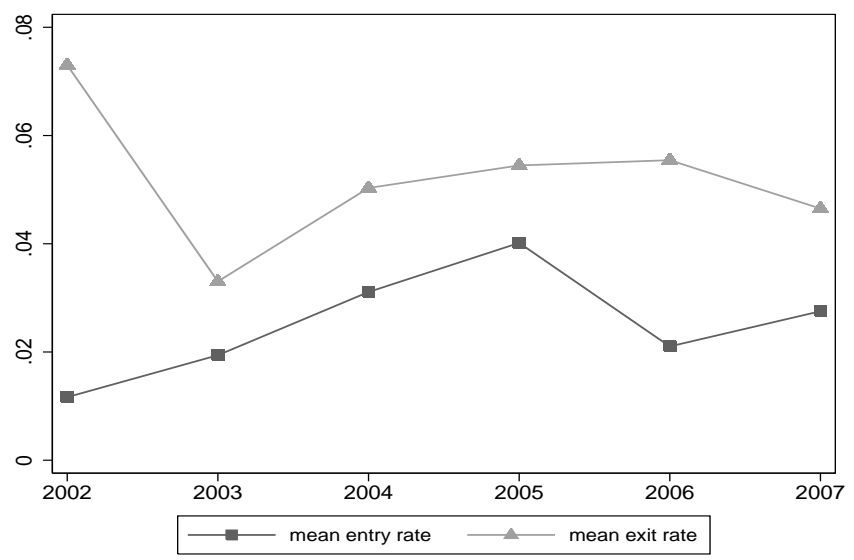

Figure 3: Mean entry and exit rates across local markets 2002-2007. 


\section{ONLINE APPENDIX \\ Entry Regulations, Welfare and Determinants of \\ Market Structure}

Florin Maican* and Matilda Orth ${ }^{\dagger}$

December 28, 2015

The online appendix consists of nine sections. Appendix A provides additional information about entry regulation in Sweden. Appendix B presents additional information about data sources. Appendix C provides additional details about the model. Appendix D provides details about the construction of the transition probabilities. Appendix E provides details about the estimation. Appendix F provides details about the estimation of the marginal cost at the store level. Appendix G reports results from demand estimation using different product baskets for small and large stores. Appendix $\mathrm{H}$ reports robustness results of entry costs using alternative entry regulation measures. Appendix I reports results of ownership and entry and exit at the store level.

\footnotetext{
${ }^{*}$ Research Institute of Industrial Economics (IFN) and University of Gothenburg, Box 640, SE-405 30, Göteborg, Sweden, Phone +46-31-786 4866, Fax +46-31-786 4154, E-mail: florin.maican@economics.gu.se

${ }^{\dagger}$ Research Institute of Industrial Economics (IFN), Box 55665, SE-102 15, Stockholm, Sweden, Phone +46-8-665 4531, Fax +46-8-665 4599, E-mail: matilda.orth@ifn.se
} 


\section{Appendix A: Entry regulation (PBA)}

On July 1, 1987, a new regulation was imposed in Sweden, the Plan and Building Act (PBA). Compared to the previous legislation, the decision process for market entry become decentralized, giving local governments power over entry in their municipality and citizens a right to appeal the decisions. Since 1987, only minor changes have been made to the PBA. From April 1, 1992, to December 31, 1996, the PBA was slightly different, prohibiting the use of buildings from counteracting efficient competition. Since 1997, the PBA has been more or less the same as it was prior to 1992. Long time lags in the planning process make it impossible to directly evaluate the impact of decisions. In practice, differences due to policy changes seem small (Swedish Competition Authority, 2001:4). Nevertheless, the PBA is considered to be one of the major entry barriers, resulting in different outcomes, e.g., price levels, across municipalities (Swedish Competition Authority, 2001:4; Swedish Competition Authority, 2004:2). Municipalities are then, through the PBA, able to put pressure on prices. Those that constrain entry have less sales per capita, while those where large and discount stores have a higher market share also have lower prices.

\section{Appendix B: Data sources}

The DELFI data. DELFI Marknadspartner AB collects daily data on retail food stores from a variety of channels: (1) public registers, the trade press, and daily press; (2) the Swedish retailers association (SSLF); (3) Kuponginlösen AB (which handles rebate coupons collected by local stores); (4) the chains' headquarters; (5) matching customer registers from suppliers; (6) telephone interviews; (7) yearly surveys; and (8) the Swedish Retail Institute (HUI). Location, 
store type, owner, and chain affiliation are double checked in corporate annual reports.

Each store has an identification number that is linked to its geographical location (address). The twelve store types, based on size, location, product assortment, and so forth, are hypermarkets, department stores, large supermarkets, large grocery stores, other stores, small supermarkets, small grocery stores, convenience stores, gas station stores, mini markets, seasonal stores, and stores under construction. We drop gas station stores from the data since these stores are located in special places and offer a limited assortment of groceries and a different product bundle than ordinary stores. There are about 1,300 gas stations in the data every year: 1,317 (2001) and 1,298 (2008).

Advantages of the data are that they are collected yearly and include the total population of stores. Sales (including VAT) and sales space are collected via yearly surveys. Owing to the survey collection, a number of missing values are substituted with the median of other stores of the same type in the same local market.

Additional descriptive statistics. Table B.1 shows that the distributions of sales space and sales are surprisingly similar across stores that belong to different firms. The median store size is 350-450 square meters for stores that the belong to the three major firms. Stores without an affiliation to the main firms are substantially smaller and have lower sales.

The majority of entrants and exits are small stores (Table B.2). Among small entrants, between 25 and 75 percent were not affiliated with any of the main four firms during the 2001-2008 period (higher at the beginning of the period). In comparison, the share of large entrants without an affiliation to any of the main firms varies between 14 and 21 percent. Regarding exits, up to half of the small stores do not belong to one of the main firms, whereas up to 20 percent is found 
for large. Sales space and sales are surprisingly similar across stores that belong to different firms.

Figure 1 shows that the substantial outflow of stores consists of mainly stores affiliated to ICA, Axfood, Coop, and Others, i.e., well established players in the market. Hard discounters and small stores that are owned by Others dominate entry, together with Axfood. Note, however, that these observations concern only the number of stores and not capacity (size/type of store).

Figures 2 and 3 show that the average entry and exit rates share similar trends for national chains, whereas the entry rate is very high for hard discounters, and the mean exit rate is high for Others.

Table B.1: Distribution of store characteristics by firm 2001-2008

\begin{tabular}{|c|c|c|c|c|c|c|c|c|}
\hline & \multicolumn{2}{|c|}{ ICA } & \multicolumn{2}{|c|}{ Axfood } & \multicolumn{2}{|c|}{ Coop } & \multicolumn{2}{|c|}{ Others } \\
\hline & $\begin{array}{l}\text { Space } \\
\left(m^{2}\right)\end{array}$ & Sales & $\begin{array}{c}\text { Space } \\
\left(m^{2}\right)\end{array}$ & Sales & $\begin{array}{c}\text { Space } \\
\left(m^{2}\right)\end{array}$ & Sales & $\begin{array}{c}\text { Space } \\
\left(m^{2}\right)\end{array}$ & Sales \\
\hline Minimum & 20 & 250 & 10 & 20 & 40 & 1,500 & 10 & 40 \\
\hline 10th percentile & 130 & 4,500 & 100 & 2,500 & 198 & 9,000 & 55 & 1,500 \\
\hline 25th percentile & 235 & 12,500 & 150 & 4,500 & 310 & 17,500 & 80 & 2,500 \\
\hline 50 th percentile & 450 & 22,500 & 350 & 12,500 & 400 & 27,500 & 116 & 3,500 \\
\hline 75th percentile & 858 & 55,000 & 1,000 & 55,000 & 900 & 45,000 & 235 & 9,000 \\
\hline 90th percentile & 1,650 & 110,000 & 1,800 & 100,500 & 1,820 & 87,500 & 500 & 17,500 \\
\hline Maximum & 10,000 & 600,000 & 11,000 & 500,000 & 11,00 & 580,000 & 15,000 & 750,000 \\
\hline Mean & 713 & 46,566 & 698 & 38,848 & 800 & 44,454 & 301 & 12,902 \\
\hline Std. deviation & 792 & 66,716 & 820 & 55,283 & 875 & 57,080 & 772 & 41,701 \\
\hline No. of obs. & \multicolumn{2}{|c|}{12,857} & \multicolumn{2}{|c|}{7,101} & \multicolumn{2}{|c|}{6,813} & \multicolumn{2}{|c|}{11,678} \\
\hline
\end{tabular}

NOTE: This table shows the distribution of number of square meters and sales of stores that belong to different firms during the period 2001-2008. Sales (incl. 12\% VAT) is measured in thousands of $2001 \mathrm{SEK}(1 \mathrm{USD}=9.39 \mathrm{SEK}, 1 \mathrm{EUR}=8.34 \mathrm{SEK})$. 
Table B.2: Entry and exit by store type and firm affiliation

\begin{tabular}{|c|c|c|c|c|c|}
\hline & \multirow[t]{2}{*}{ All } & \multicolumn{2}{|c|}{ Small stores } & \multicolumn{2}{|c|}{ Large stores } \\
\hline & & number & $\begin{array}{l}\text { share not affiliated } \\
\text { to the main firms }\end{array}$ & number & $\begin{array}{l}\text { share not affiliated } \\
\text { to the main firms }\end{array}$ \\
\hline \multicolumn{6}{|c|}{ A. Entrants } \\
\hline \multicolumn{6}{|c|}{2001} \\
\hline 2002 & 71 & 60 & 0.783 & 11 & 0.000 \\
\hline 2003 & 113 & 93 & 0.612 & 20 & 0.150 \\
\hline 2004 & 128 & 118 & 0.305 & 10 & 0.200 \\
\hline 2005 & 167 & 153 & 0.301 & 14 & 0.143 \\
\hline 2006 & 126 & 96 & 0.344 & 30 & 0.167 \\
\hline 2007 & 123 & 95 & 0.316 & 28 & 0.214 \\
\hline 2008 & 102 & 80 & 0.250 & 22 & 0.000 \\
\hline \multicolumn{6}{|c|}{$\overline{\bar{B} \text { B. Exits }}$} \\
\hline 2001 & 385 & 366 & 0.511 & 19 & 0.053 \\
\hline 2002 & 157 & 142 & 0.387 & 15 & 0.200 \\
\hline 2003 & 240 & 218 & 0.408 & 22 & 0.091 \\
\hline 2004 & 257 & 240 & 0.500 & 17 & 0.176 \\
\hline 2005 & 242 & 209 & 0.478 & 33 & 0.181 \\
\hline 2006 & 198 & 181 & 0.530 & 17 & 0.059 \\
\hline 2007 & 193 & 171 & 0.544 & 22 & 0.181 \\
\hline \multicolumn{6}{|l|}{2008} \\
\hline
\end{tabular}



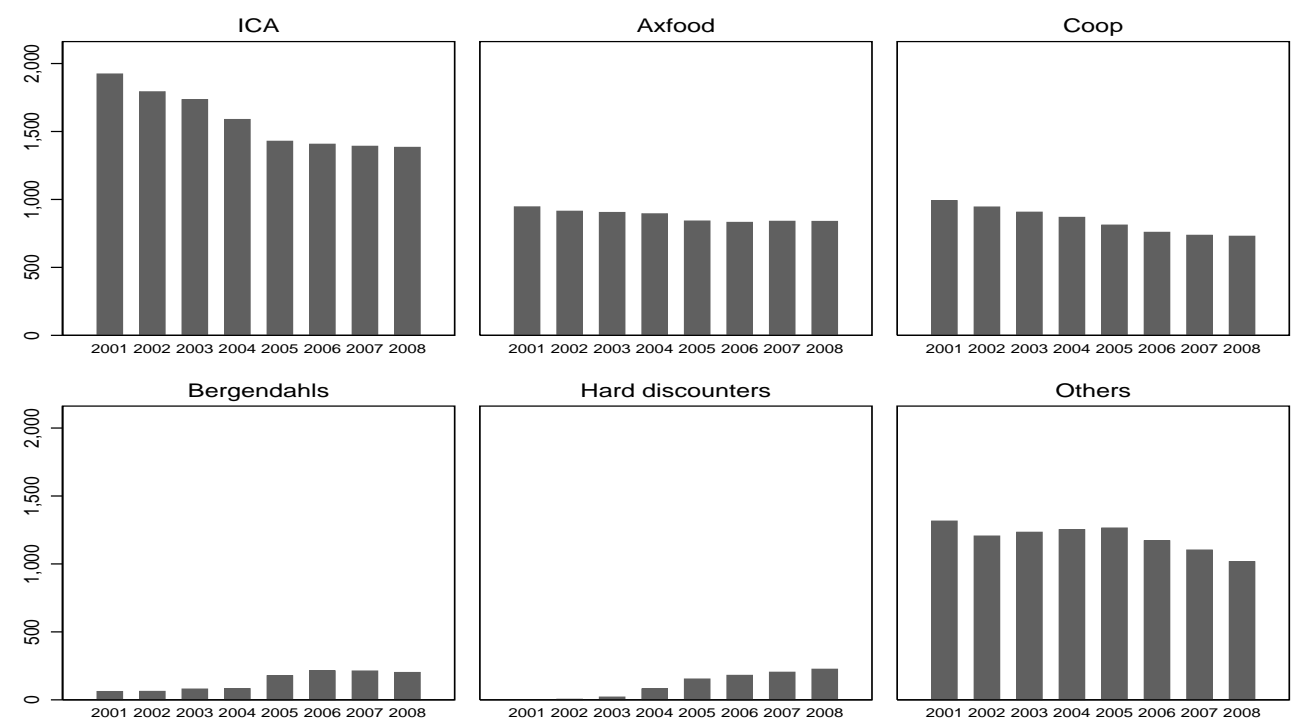

Figure 1: Total number of stores by firm affiliation 2001-2008. 


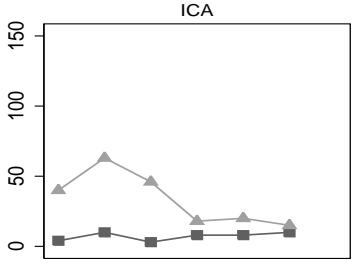

Bergendahls

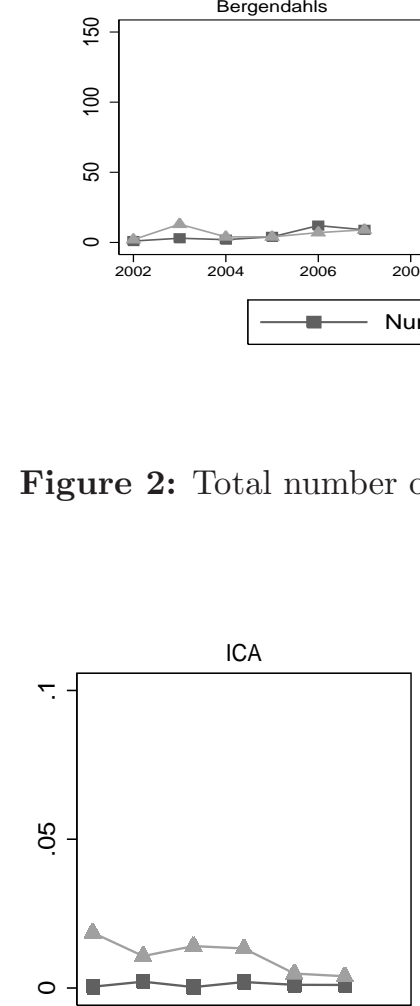

$\longrightarrow$ Entry rate
Axfood

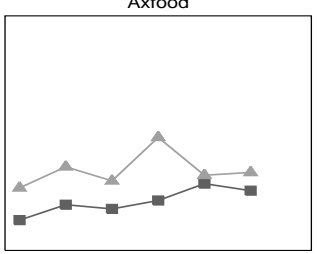

Hard discounters

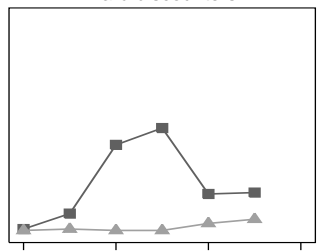

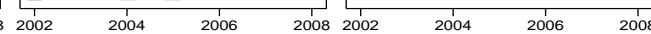

Coop

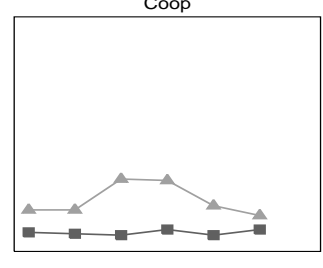

Others

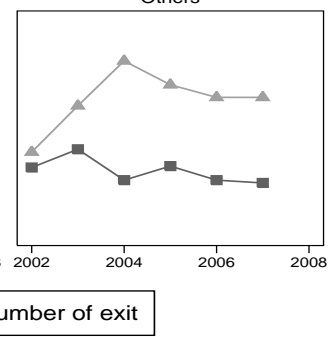

Figure 2: Total number of entries and exits by firm affiliation 2002-2007.

Bergendahls
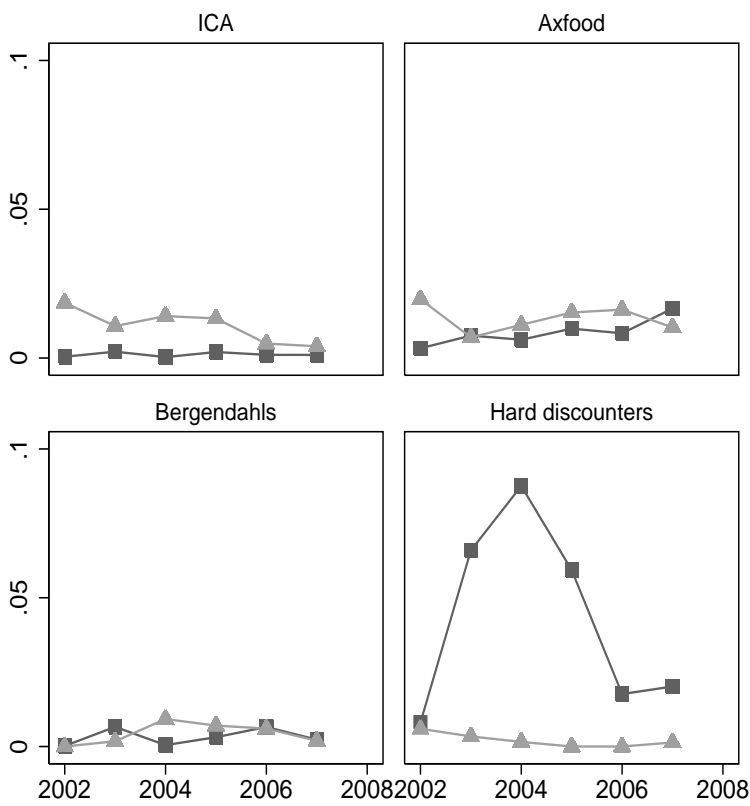

Hard discounters

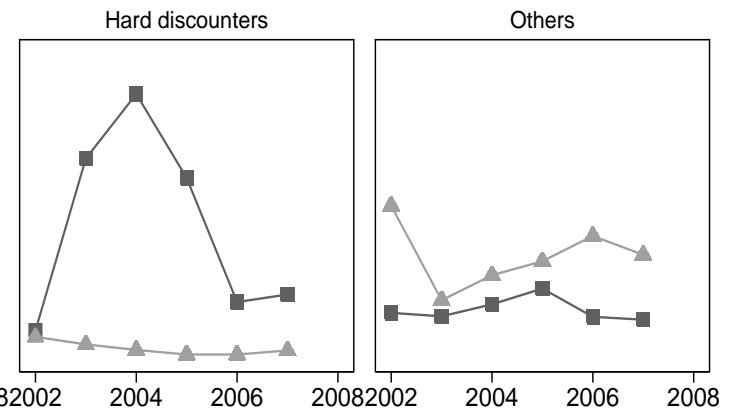

Figure 3: Mean entry and exit rates by firm affiliation and local markets 2002-2007. 
Price data. The data on prices are collected by the Swedish National Organization of Pensioners (PRO) and contain yearly price information for approximately 30 products in about 1,000 stores during the 2003-2008 period. ${ }^{1}$ The sample thus covers roughly 20 percent of the total number of stores. Stores of different sizes, formats and firms are investigated across the entire country. The "regular price", i.e., the price is without temporary promotions or discount campaigns (due to, for example, loyalty cards) is collected for each product. We form a product basket by selecting eleven products that are available in all stores and do not change their characteristics and package size. These products are as follows: sugar (Strosocker Dansukker $2 \mathrm{~kg}$ ); cereals (Havregryn fiber AXA 800 g); mashed potatoes (Potatismos Felix); macaroni (Snabbmakaroner Kungsornen $1 \mathrm{~kg}$ ); coffee (Gevalia mellan brygg 500 g); chocolate milk (O'boy Kraft 500 g); bread (Husman Wasabrod 500 g); biscuits (Guldmarie Goteborgskex 200 g); breakfast cereals (Familjemusli orig Finax); margarine (Bregott 600 g); caviar (Kalle kaviar Abba $190 \mathrm{~g}$ ). Table B.3 shows the summary statistics of the price of a basket that contains one package of each of these eleven products. Large stores offer a cheaper price than small ones for the basket. For both store types, the difference between the 75 th and the 25 th percentile is about 30 SEK. Table B.4 presents the distribution of the basket prices for small and large stores belonging to main firms. First, for all firms, large stores offer lower prices. Second, Bergendahls offers a lower median price for our selected basket than other firms. Third, the difference between the median price from a large store and from a

\footnotetext{
${ }^{1}$ Because our store data cover the 2001-2008 period, we compute price predictions in 2001 and 2002. We model the price as an AR(1) process with exogenous controls such us local market demand shifters. This is not restrictive since we only need predicted prices for 2 years. In addition, our demand estimates are robust to the sample choice (2001-2008 or 2003-2008). We prefer to use the full sample (2001-2008) because we use this sample when computing transition matrices in the dynamic setting.
} 
small store is less than 10 SEK. Fourth, ICA offers the minimum prices among the main 4 firms. The figures show that we have price variation across store types and firms.

Table B.3: Descriptive statistics of the basket price by store type, 2001-2008

\begin{tabular}{lccccc}
\hline \hline $\begin{array}{l}\text { Store } \\
\text { type }\end{array}$ & Minimum & Q25 & Q50 & Q75 & Maximum \\
\hline Small & 98.50 & 192.72 & 211.90 & 222.83 & 327.30 \\
Large & 152.80 & 188.15 & 203.85 & 215.50 & 278.50 \\
\hline \hline
\end{tabular}
basket consists of eleven products.

Table B.4: Descriptive statistics of the basket price by firm and store type, 2001-2008

\begin{tabular}{lccccc}
\hline \hline Store type & Minimum & Q25 & Q50 & Q75 & Maximum \\
\hline \hline Panel A: ICA & & & & & \\
\hline Small & 159.00 & 191.85 & 210.83 & 221.25 & 268.80 \\
Large & 152.80 & 187.37 & 203.90 & 215.05 & 266.90 \\
\hline Panel B: Axfood & & & & \\
\hline Small & 170.20 & 192.53 & 213.18 & 224.03 & 304.10 \\
Large & 165.39 & 192.30 & 204.30 & 215.68 & 278.50 \\
\hline Panel C: Bergendahls & & & & \\
\hline Small & 166.80 & 190.07 & 201.00 & 220.63 & 263.70 \\
Large & 164.23 & 186.25 & 196.39 & 210.62 & 262.90 \\
\hline Panel D: Coop & & & & \\
\hline Small & 168.60 & 195.40 & 213.90 & 225.80 & 327.30 \\
Large & 164.23 & 188.06 & 204.49 & 216.39 & 266.90 \\
\hline Panel E: Others & & & & \\
\hline Small & 98.50 & 192.72 & 213.05 & 222.37 & 275.30 \\
Large & 163.90 & 186.72 & 206.68 & 219.29 & 263.70 \\
\hline \hline
\end{tabular}




\section{Appendix C: Model: Continuation values, entry val- ues and equilibrium}

Incumbents and sell-off value. Section 3 in the paper presents the model using fixed-costs. The model can be rewritten to estimate sell-off values instead of fixed costs. The value function of an incumbent store of type $z$ is given by the Bellman equation

$$
\begin{aligned}
V_{z}\left(n_{z}, n_{-z}, \mathbf{y}, \phi_{z} ; \boldsymbol{\theta}\right)= & \max \left\{\pi_{z}\left(n_{z}, n_{-z}, \mathbf{y} ; \boldsymbol{\theta}\right)+\beta \phi_{z}, \pi_{z}\left(n_{z}, n_{-z}, \mathbf{y} ; \boldsymbol{\theta}\right)+\right. \\
& \left.\beta V C_{z}\left(n_{z}, n_{-z}, \mathbf{y} ; \boldsymbol{\theta}\right)\right\},
\end{aligned}
$$

where $\pi_{z}(\cdot)$ is the profit function; $V C_{z}(\cdot)$ is the continuation value; $\phi_{z}$ is the sell-off value; and $0<\beta<1$ is the discount factor. Incumbents know their scrap value $\phi_{z}$ but not the number of entrants and exits, prior to making their decision.

Incumbents perceptions. The continuation value, $V C_{z}(\cdot)$, is obtained by taking the expectation over the number of entrants, exits, and possible values of the profit shifters

$$
\begin{aligned}
V C_{z}\left(n_{z}, n_{-z}, \mathbf{y} ; \boldsymbol{\theta}\right)= & \sum_{e_{z}, e_{-z}, x_{z}, x_{-z}, \mathbf{y}} \int_{\phi_{z}^{\prime}} V_{z}\left(n_{z}+e_{z}-x_{z}, n_{-z}+e_{-z}-x_{-z},\right. \\
& \left.\mathbf{y}, \phi_{z}^{\prime} ; \boldsymbol{\theta}\right) p_{z}^{c}\left(e_{z}, e_{-z}, x_{z}, x_{-z} \mid n_{z}, n_{-z}, \mathbf{y}, \lambda_{z}^{c}=1\right) \\
& p\left(\mathbf{y}^{\prime} \mid \mathbf{y}\right) p\left(d \phi_{z}^{\prime}\right)
\end{aligned}
$$

where $p_{z}^{c}(\cdot)$ is a $z$ - incumbent's perception of the rivals' type decisions $\left(e_{z}, e_{-z}, x_{z}, x_{-z}\right)$ conditional on itself continuing, i.e., $\lambda_{z}^{c}=1$. The optimal policy for an incumbent is to exit if the draw of the fixed-cost (or sell-off value) is larger than the value of continuing in the market, which gives the probability of exit $\operatorname{Pr}\left(\phi_{z}>V C_{z}\left(n_{z}, n_{-z}, \mathbf{y} ; \boldsymbol{\theta}\right)\right)=1-F^{\phi_{z}}\left(V C_{z}\left(n_{z}, n_{-z}, \mathbf{y} ; \boldsymbol{\theta}\right)\right)$. 
Entrants perceptions. Potential entrants maximize the expected discounted future profits and enter if they can cover their sunk costs. They start to operate in the next period. The value of entry is

$$
\begin{aligned}
V E_{z}\left(n_{z}, n_{-z}, \mathbf{y} ; \boldsymbol{\theta}\right)= & \sum_{e_{z}, e_{-z}, x_{z}, x_{-z}, \mathbf{y}} \int_{\phi_{z}^{\prime}} V_{z}\left(n_{z}+e_{z}-x_{z}, n_{-z}+e_{-z}-x_{-z},\right. \\
& \left.\mathbf{y}, \phi_{z}^{\prime} ; \boldsymbol{\theta}\right) p_{z}^{e}\left(e_{z}, e_{-z}, x_{z}, x_{-z} \mid n_{z}, n_{-z}, \mathbf{y}, \lambda_{z}^{e}=1\right) \\
& p\left(\mathbf{y}^{\prime} \mid \mathbf{y}\right) p\left(d \phi_{z}^{\prime}\right)
\end{aligned}
$$

where $p_{z}^{e}(\cdot)$ is a potential entrant's perceptions of the number of entrants and exits of each type conditional on entering the market. Entry occurs if the draw from the distribution of sunk costs is smaller than the value of entry, which results in the probability of entry being $\operatorname{Pr}\left(\kappa_{z}<V E_{z}\left(n_{z}, n_{-z}, \mathbf{y} ; \boldsymbol{\theta}\right)\right)=$ $F^{\kappa_{z}}\left(V E_{z}\left(n_{z}, n_{-z}, \mathbf{y} ; \boldsymbol{\theta}\right)\right)$. Potential entrants choose to operate a store of type $z$ if the expected profits are higher than those for all other types and the outside option. Hence, first, we have the condition that the entry value needs to be larger than the draw of the entry cost. Then, we have that the type (location) decision needs to give the highest expected discounted future profits among all type alternatives:

$$
\begin{gathered}
V E_{z}\left(n_{z}, n_{-z}, \mathbf{y} ; \boldsymbol{\theta}\right) \geq \kappa_{z} \\
\beta V E_{z}\left(n_{z}, n_{-z}, \mathbf{y} ; \boldsymbol{\theta}\right) \geq \beta V E_{-z}\left(n_{z}, n_{-z}, \mathbf{y} ; \boldsymbol{\theta}\right) .
\end{gathered}
$$

Equilibrium. Incumbents and potential entrants make simultaneous moves, and they both form the perceptions of entry and exit among rivals. In equilibrium, these perceptions need to be consistent with stores' actual behavior. The incumbents' perceptions of rival incumbents' behavior need to be the same for all rivals of the same type. That is, all incumbents of a given type have the 
same probability of exit, which is the probability that the draw of the exit cost is larger than the value of continuing. Similarly, all potential entrants have the same probability of entering with a given type, i.e., they have the same probability that the draw of the entry cost is smaller than the value of entry. Thus, again the perceptions are the same for all rivals of the same store type.

For incumbents, we need to construct the perceptions of $p_{z}^{c}$ in equation (C2). Conditional on a $z$-incumbent continuing, we have to compute the perceived probabilities of facing a particular number of entrants and exits of each type $p_{z}^{c}\left(e_{z}, e_{-z}, x_{z}, x_{-z} \mid n_{z}, n_{-z}, \mathbf{y}, \lambda_{z}^{c}=1\right)$. That is, the probability that the exit draw is larger than the type-location continuation value $\phi_{z}>V C_{z}\left(n_{z}, n_{-z}, \mathbf{y} ; \boldsymbol{\theta}\right)$ is

$$
\begin{aligned}
p_{z}^{c}\left(e_{z}, e_{-z}, x_{z}, x_{-z} \mid n_{z}, n_{-z}, \mathbf{y}, \lambda_{z}^{c}=1\right)= & p_{z}^{c}\left(e_{z}, e_{-z} \mid n_{z}, n_{-z}, \mathbf{y}, \lambda_{z}^{e}=1\right) \\
& g_{z}^{c}\left(x_{z}, n_{z}-1 \mid n_{z}, n_{-z}, \mathbf{y}\right) \\
& g_{-z}^{c}\left(x_{-z}, n_{-z} \mid n_{z}, n_{-z}, \mathbf{y}\right) .
\end{aligned}
$$

The perceptions of entry conditional on that they enter $p_{z}^{c}(\cdot)$ and the perceptions of exit of the same type $g_{z}^{c}(\cdot)$ and of the rival type $g_{-z}^{c}(\cdot)$ all need to be consistent with the equilibrium behavior. The assumption that competitors are identical in type implies that incumbents' perceptions of competitors' exit from each type are given by the multinomial logit probabilities in the case of more than two choices and by the binomial distribution in the case of two choices.

Potential entrants of each type are identical up to the draw of the sunk cost, so in equilibrium, all potential entrants of each type need to have the same 
probability of entry. The perceptions are given by

$$
\begin{aligned}
p_{z}^{e}\left(e_{z}, e_{-z}, x_{z}, x_{-z} \mid n_{z}, n_{-z}, \mathbf{y}, \lambda_{z}^{e}=1\right)= & p_{z}^{e}\left(e_{z}, e_{-z} \mid n_{z}, n_{-z}, \mathbf{y}, \lambda_{z}^{e}=1\right) \\
& g_{z}^{e}\left(x_{z}, n_{z} \mid n_{z}, n_{-z}, \mathbf{y}\right) \\
& g_{-z}^{e}\left(x_{-z}, n_{-z} \mid n_{z}, n_{-z}, \mathbf{y}\right),
\end{aligned}
$$

where $p_{z}^{e}(\cdot)$ are the perceptions of the entrants conditional on that they enter, while $g_{z}^{e}(\cdot)$ and $g_{-z}^{e}(\cdot)$ are the perceptions of exit of the same and rival types.

The solution concept is a Markov Perfect Equilibrium. Yet, there might exist more than one equilibrium. As in $\mathrm{POB}$, it is guaranteed that in the recurrent class, there is only one profile of equilibrium policies that is consistent with a given data-generating process. The data will thus select the equilibrium that is played. As POB argue, the correct equilibrium will be selected if samples are large enough. For this purpose, the present paper takes advantage of the detailed data that we have access to, covering the total population of stores in Sweden for a long period of time.

\section{Appendix D: Transition probabilities}

Incumbents and sell-off value. An incumbent that continues will get the continuation value

$$
V C_{z}(\mathbf{s} ; \boldsymbol{\theta})=E_{\mathbf{s}^{\prime}}^{c}\left[\pi_{z}\left(\mathbf{s}^{\prime} ; \boldsymbol{\theta}\right)+\beta E_{\phi_{z}^{\prime}}\left(\max \left\{V C_{z}\left(\mathbf{s}^{\prime} ; \boldsymbol{\theta}\right), \phi_{z}^{\prime}\right\} \mid \mathbf{s}^{\prime}\right)\right]
$$

where $\mathbf{s}=\left(n_{z}, n_{-z}, \mathbf{y}\right)$ and $\mathbf{s}^{\prime}=\left(n_{z}^{\prime}, n_{-z}^{\prime}, \mathbf{y}^{\prime}\right)$. An incumbent will exit if the draw of the sell-off value is larger than the continuation value in a given state $\mathbf{s}$, i.e., 
$p_{z}^{x}(\mathbf{s})=\operatorname{Pr}\left(\phi_{z}^{\prime}>V C_{z}\left(\mathbf{s}^{\prime} ; \boldsymbol{\theta}\right)\right)$. Thus

$$
E_{\phi_{z}^{\prime}}\left(\max \left\{V C_{z}\left(\mathbf{s}^{\prime} ; \boldsymbol{\theta}\right), \phi_{z}^{\prime}\right\} \mid \mathbf{s}^{\prime}\right)=\left(1-p_{z}^{x}\right) V C_{z}\left(\mathbf{s}^{\prime} ; \boldsymbol{\theta}\right)+p_{z}^{x} E\left[\phi_{z}^{\prime} \mid \phi_{z}^{\prime}>V C_{z}\left(\mathbf{s}^{\prime} ; \boldsymbol{\theta}\right)\right] .
$$

If we assume that $\phi_{z}$ has an exponential distribution, we get $E\left[\phi_{z}^{\prime} \mid \phi_{z}^{\prime}>V C_{z}\left(\mathbf{s}^{\prime} ; \boldsymbol{\theta}\right)\right]=$ $V C_{z}\left(\mathbf{s}^{\prime}\right)+\sigma_{z}$, which we substitute into (D-9). Using (D-8), we then get

$V C_{z}(\mathbf{s} ; \boldsymbol{\theta})=E_{\mathbf{s}^{\prime}}^{c}\left[\pi_{z}\left(\mathbf{s}^{\prime} ; \boldsymbol{\theta}\right)+\beta E_{\phi_{z}^{\prime}}\left(\max \left\{\left(1-p_{z}^{x}\right) V C_{z}\left(\mathbf{s}^{\prime} ; \boldsymbol{\theta}\right)+p_{z}^{x}\left(V C_{z}\left(\mathbf{s}^{\prime} ; \boldsymbol{\theta}\right)+\sigma_{z}\right)\right\}\right)\right]$,

where $\sigma_{z}$ is a parameter in the exponential distribution that represents the inverse of the mean. We now define the continuation values, profits, and exit probabilities as vectors, i.e., $\boldsymbol{V} \boldsymbol{C}_{z}(\cdot), \boldsymbol{\pi}_{z}$, and $\boldsymbol{p}_{z}^{x}$. Furthermore, we define a matrix of transition probabilities $\boldsymbol{W}_{z}^{c}$ that indicates the transition from state $\mathbf{s}=\left(n_{z}, n_{-z}, \mathbf{y}\right)$ to state $\mathbf{s}^{\prime} \neq \mathbf{s}$ for type $z$

$$
\boldsymbol{V} \boldsymbol{C}_{z}(\cdot)=\boldsymbol{W}_{z}^{c}\left[\boldsymbol{\pi}_{z}+\beta \boldsymbol{V} \boldsymbol{C}_{z}(\cdot)+\beta \sigma_{z} \boldsymbol{p}_{z}^{x}\right]
$$

There is no dependence over time in the transition probabilities. ${ }^{2}$

Incumbents: Empirical transition probabilities. To compute the continuation value, we need to calculate the expected discounted future profits that the store would gain in alternative future states. We then take weighted averages for those stores that actually continued from state $\mathbf{s}$. The idea is to use average discounted profits that are actually earned by stores that continue from state s, i.e., to insert consistent estimates of $\boldsymbol{W}_{z}^{c}$ and $\boldsymbol{p}_{z}^{x}$ into (D-11) in order to get consistent estimates of $\boldsymbol{V} \boldsymbol{C}_{z}(\cdot)$.

We average over the states in the recurrent class. Let $R$ be the set of periods

${ }^{2}$ The presence of serially correlated unobservables is discussed in detail in the empirical implementation in Section 4. 
in state $\mathbf{s}=\left(n_{z}, n_{-z}, \mathbf{y}\right)$ :

$$
R(\mathbf{s})=\left\{r: \mathbf{s}_{r}=\mathbf{s}\right\},
$$

where $\mathbf{s}_{r}=\left(n_{r, z}, n_{r,-z}, \mathbf{y}_{r}\right)$. Using the Markov property and summing over the independent draws of the probability of exit, we obtain consistent estimates of exit probabilities:

$$
\tilde{p}_{z}^{x}(\mathbf{s})=\frac{1}{\# R(\mathbf{s})} \sum_{r \in R(\mathbf{s})} \frac{x_{r, z}}{n_{z}} .
$$

Let $W_{\mathbf{s}, \mathbf{s}^{\prime}}^{c}$ be the probability that an incumbent transitions to $\mathbf{s}^{\prime}=\left(n_{z}^{\prime}, n_{-z}^{\prime}, \mathbf{y}^{\prime}\right)$ conditional on continuing in $\mathbf{s}=\left(n_{z}, n_{-z}, \mathbf{y}\right)$. Consistent estimates for incumbents' transition probability from state $\mathbf{s}$ to $\mathbf{s}^{\prime}$ are given by

$$
\tilde{W}_{\mathbf{s}, \mathbf{s}^{\prime}}^{c}=\frac{\sum_{r \in R(\mathbf{s})}\left(n_{z}-x_{r, z}\right) \mathbf{1}_{\mathbf{s}_{r+1}=\mathbf{s}^{\prime}}}{\sum_{r \in R(\mathbf{s})}\left(n_{z}-x_{r, z}\right)} .
$$

Both $\tilde{p}_{z}^{x}(\mathbf{s})$ and $\tilde{W}_{\mathbf{s}, \mathbf{s}^{\prime}}^{c}$ will converge in probability to $p_{z}^{x}(\mathbf{s})$ and $W_{\mathbf{s}, \mathbf{s}^{\prime}}^{c}$ as $R(\mathbf{s}) \rightarrow \infty$. The transitions are weighted by the number of incumbents that continue in order to capture the fact that incumbents' calculations are conditional on continuing. Now, we use equation (D-11) to get estimates of $\boldsymbol{V} \boldsymbol{C}_{z}(\cdot)$ as a function of $\boldsymbol{\pi}_{z}, \tilde{\boldsymbol{p}}_{z}^{x}$ and $\tilde{\boldsymbol{W}}_{z}^{c}$ when modeling sell-off value:

$$
\widehat{\boldsymbol{V C}}_{z}(\cdot)=\left[I-\beta \tilde{\boldsymbol{W}}_{z}^{c}\right]^{-1} \tilde{\boldsymbol{W}}_{z}^{c}\left[\boldsymbol{\pi}_{z}+\beta \sigma_{z} \tilde{\boldsymbol{p}}_{z}^{x}\right]
$$

where $I$ is the identity matrix. Modeling fixed-costs, we have (see Section 3)

$$
\widehat{\boldsymbol{V C}}_{z}(\cdot)=\left[I-\beta \tilde{\boldsymbol{W}}_{z}^{c}\right]^{-1} \tilde{\boldsymbol{W}}_{z}^{c}\left[\boldsymbol{\pi}_{z}-\beta \sigma_{z}\left(1-\tilde{\boldsymbol{p}}_{z}^{x}\right)\right] .
$$

The calculation of the continuation values includes inversion of the transition matrix. $\widehat{V C C}_{z}(\cdot)$ is the mean of the discounted values of the actual returns by 
players, creating a direct link to the data. Since $\tilde{\boldsymbol{W}}_{z}^{c}$ and $\tilde{\boldsymbol{p}}_{z}^{x}$ are independent of the parameters (for a known $\beta$ ), they only need to be constructed once. The computational burden decreases because the transitions are only constructed in the beginning of the estimation routine. The burden increases, on the other hand, in the number of states, mainly due to the inversion of the transition matrix. ${ }^{3}$

Entrants: Empirical transition probabilities. We follow the same approach for entrants as for incumbents and define $\boldsymbol{W}_{z}^{e}$ as the transition matrix that gives the probability that an entrant starts operating at $\mathbf{s}^{\prime}$ conditional on continuing in $\mathbf{s :}$

$$
\tilde{W}_{\mathbf{s}, \mathbf{s}^{\prime}}^{e}=\frac{1}{\# R(\mathbf{s})} \frac{\sum_{r \in R(\mathbf{s})}\left(e_{r, z}\right) \mathbf{1}_{\mathbf{s}_{r+1}=\mathbf{s}^{\prime}}}{\sum_{r \in R(\mathbf{s})}\left(e_{r, z}\right)} .
$$

The expected value of entry is then

$$
\begin{aligned}
\widehat{\boldsymbol{V E}}_{z}(\cdot)= & {\left[\tilde{\boldsymbol{W}}_{z}^{e}+\beta \tilde{\boldsymbol{W}}_{z}^{e}\left[I-\beta \tilde{\boldsymbol{W}}_{z}^{c}\right]^{-1} \tilde{\boldsymbol{W}}_{z}^{c}\right] \boldsymbol{\pi}_{z} } \\
& +\left[\beta \tilde{\boldsymbol{W}}_{z}^{e} \beta \tilde{\boldsymbol{W}}_{z}^{c}\left[I-\beta \tilde{\boldsymbol{W}}_{z}^{c}\right]^{-1} \tilde{\mathbf{p}}_{z}^{x}+\beta \tilde{\boldsymbol{W}}_{z}^{e} \tilde{\mathbf{p}}_{z}^{x}\right] \sigma_{z} .
\end{aligned}
$$

\section{Appendix E: Details on estimation}

The empirical transition probability matrices used in the estimation are sparse. To compute the value functions for the states that are not observed in the data, we use a "smoothing" technique as suggested by Pakes et al. (2007). POB use kernel estimator. This paper uses b-splines and ordinary least square estimator. To estimate cost parameters, we use two different GMM estimators, i.e., an indirect inference estimator and a minimum distance estimator. The cost estimates

\footnotetext{
${ }^{3}$ The number of states depends directly on the number of types/locations and on the way in which we discretize the exogenous demand and cost shifters.
} 
are robust to the choice of estimator.

Indirect inference: In case of indirect inference, we run ordinary least square regressions on entry and exit probabilities from the data and from the model, i.e. $\mathbf{p}=\mathbf{s} \boldsymbol{\rho}$, and save the estimated coefficients $\boldsymbol{\rho}$ (data) and $\boldsymbol{\rho}(\boldsymbol{\theta})$ (model). The criterion function minimizes the distance between the regression coefficients:

$$
\hat{\boldsymbol{\theta}}=\arg \max _{\boldsymbol{\theta}}[\hat{\boldsymbol{\rho}}-\hat{\boldsymbol{\rho}}(\boldsymbol{\theta})]^{\prime} \mathbf{A}_{R}[\hat{\boldsymbol{\rho}}-\hat{\boldsymbol{\rho}}(\boldsymbol{\theta})]
$$

where $\mathbf{A}_{R}$ is the weighting matrix, i.e., identity matrix or $\operatorname{Var}[\boldsymbol{\rho}]^{-1}$.

Minimum distance estimator: Let $\hat{\mathbf{p}}$ be the vector of exit and entry probabilities that are observed in the data for each type and that are, therefore, used to estimate the transition matrices. The vector of theoretical probabilities $\hat{\mathbf{q}}$ is obtained from the assumed cost distributions and computed value functions. The minimum distance estimator is defined as

$$
\hat{\boldsymbol{\theta}}=\arg \max _{\boldsymbol{\theta}}[\hat{\mathbf{p}}-\hat{\mathbf{q}}(\boldsymbol{\theta})]^{\prime} \mathbf{A}_{R}[\hat{\mathbf{p}}-\hat{\mathbf{q}}(\boldsymbol{\theta})]
$$

where $\mathbf{A}_{R}$ is the weighting matrix that is defined by the following blocks

$$
\mathbf{A}_{R}(j, j)=\left[\begin{array}{cccc}
\frac{\# R\left(\mathbf{s}_{1}\right)^{2}}{R^{2}} & \frac{2 \# R\left(\mathbf{s}_{1}\right) \# R\left(\mathbf{s}_{2}\right)}{R^{2}} & \cdots & \frac{2 \# R\left(\mathbf{s}_{1}\right) \# R\left(\mathbf{s}_{S}\right)}{R^{2}} \\
\vdots & \vdots & \vdots & \vdots \\
\frac{\# R\left(\mathbf{s}_{S}\right) \# R\left(\mathbf{s}_{1}\right)}{R^{2}} & \frac{2 \# R\left(\mathbf{s}_{S}\right) \# R\left(\mathbf{s}_{2}\right)}{R^{2}} & \cdots & \frac{\# R\left(\mathbf{s}_{S}\right)^{2}}{R^{2}}
\end{array}\right]
$$

where $\# R(\mathbf{s})$ is the number of observations in state $\mathbf{s}$ and $R$ is the total number of observations. The matrix $\mathbf{A}_{R}$ reduces the fine bias, but is not the asymptotic optimal matrix. 


\section{Appendix F: Estimation of the marginal cost at the store level}

In Section 5 in the paper, we need to compute the values of marginal costs for small and large stores at the states that are not observed in the data. To obtain the marginal cost predictions for these states, we use the observed values of the marginal cost predicted by the demand system and a reduced-form linear specification, i.e.,

$$
m c_{j m t}=\mathbf{x}_{j m t}^{\prime} \gamma+\epsilon_{j m t}
$$

where the vector $\mathbf{x}_{j m t}^{\prime}$ includes store-type dummies, market fixed-effects, distance to the distribution center, and average wage that are likely to be exogenous or predetermined. The estimation results in Table F.1 show that the marginal cost for large stores is on average SEK 16 lower than for small stores. Table F.2 shows summary statistics for the observed marginal cost values from the demand system and the predicted value using the above linear specification. The statistics are presented for both restrictive and liberal markets. The linear specification accurately predicts the observed marginal cost values. For example, the observed and the predicted means and medians are similar.

Table F.1: Estimation of reduced-form marginal cost specification

\begin{tabular}{lcccr}
\hline \hline & \multicolumn{2}{c}{ Restrictive } & \multicolumn{2}{c}{ Liberal } \\
& Estimated & t-stat & Estimated & t-stat \\
\hline \multirow{2}{*}{ Large store } & -16.334 & -30.247 & -15.329 & -29.422 \\
& & & & \\
Local market controls & Yes & Yes & Yes & Yes \\
$R^{2}$ & 0.14 & & 0.13 & \\
\hline
\end{tabular}

Note: Local market controls include store-type dummies, market fixedeffects, average wage, and distance to the distribution center. 
Table F.2: Distribution of the marginal cost estimates from the demand system and predicted values using a linear specification

\begin{tabular}{lrrrr}
\hline \hline & \multicolumn{2}{c}{ Restrictive } & \multicolumn{2}{c}{ Liberal } \\
& Estimated & Prediction & Estimated & Prediction \\
& $(1)$ & $(2)$ & $(1)$ & $(2)$ \\
\hline Mean & 186.09 & 186.09 & 186.39 & 186.39 \\
Std. & 22.61 & 8.59 & 25.91 & 9.39 \\
& & & & \\
Q25 & 170.82 & 179.54 & 171.66 & 180.24 \\
Q50 & 190.30 & 189.11 & 187.84 & 187.76 \\
Q75 & 201.13 & 192.74 & 201.56 & 193.66 \\
& & & & \\
$R^{2}$ & & 0.14 & & 0.13 \\
\hline
\end{tabular}

Note: Column (1) shows estimated marginal cost from the demand system. Column (2) shows predicted values of marginal cost using the following linear specification: $m c_{j m t}=\mathbf{x}_{j m t}^{\prime} \gamma+\epsilon_{j m t}$, where the vector $\mathbf{x}_{j m t}^{\prime}$ includes store-type dummies, market fixed-effects, distance to the distribution center, and average wage that are likely to be exogenous or predetermined.

\section{Appendix G: Demand estimation using different prod- uct baskets for small and large stores}

There are pros and cons of using separate product baskets for small and large stores. We start with the advantages. The main advantage is that we can get close to the observed situation in the markets where large stores offer more products than small stores and consumers might have a large basket when buying from large stores. Using separate baskets might result is more intense store type competition, but this is an empirical questions. On the other hand, there are disadvantages using separate baskets. First, we do not use the full information available in the data, i.e., the data contain basic products sold in all stores. 
Second, by using a small product basket for small stores we have a low price variation across small stores that can affect the identification. Third, it might be difficult to understand whether large stores have lower marginal cost that small stores. In addition, it is difficult to do a good prediction for marginal costs for each store type for the unobserved states when there are large marginal cost differences between small and large stores.

Table G.1 presents estimation results from the demand system using a small basket for small stores and a large basket for large stores. The main findings, i.e., when using the large basket for both store types, are robust to using separate product baskets for small and large stores. For example, the price coefficients are similar (-0.01 vs -0.006) and consumers have higher utility shopping from ICA and Coop. The lower price variation across small stores, due to fewer products in the basket, results in lower own- and cross-price elasticities (in absolute values) than using the larger basket for all stores. This indicates that small stores compete in other dimensions than price, e.g. location. Most importantly, the asymmetric store type competition is robust to the use of different product baskets.

Table G.1: Estimated parameters of the demand equation: Nested logit with different product baskets

\begin{tabular}{lrr}
\hline \hline & Estimated & Std. \\
\hline Log of space $\left(m^{2}\right)$ & 0.5913 & 0.1345 \\
Log of income & 0.3165 & 0.1797 \\
Log of income squared & -0.0745 & 0.0025 \\
ICA & 2.2610 & 0.2377 \\
Axfood & 1.7734 & 0.1366 \\
Coop & 2.1139 & 0.2328 \\
Bergendahls & 1.6307 & 0.2177 \\
Price & -0.0063 & 0.0006 \\
Market share (grp) & 0.3710 & 0.1685 \\
\hline NOTE: The average price of a type in other local markets and \\
average wages are used as instruments for prices. The log of \\
the average market share in its own group in the other local \\
markets is used as instrument for the market share within \\
group.
\end{tabular}




\section{Appendix H: Robustness results of entry costs using alternative regulation measures}

In addition to the results presented in Section 5 in the paper, we present robustness estimates of the entry costs and fixed costs using different regulation measures. It is important to emphasize that a change in regulation measure affects both profits and transition probabilities. To keep the presentation of the robustness short, we show the cost estimates. Table H.1 shows the estimation results using a regulation index with equal weights and the share of non-socialist seats as a measure of the stringency of regulation. The findings show that our results in Section 5 are robust to different alternatives of the entry regulation measure. While the magnitudes of the cost measures vary due to changes in both store profits and transition probabilities, the main results remain robust. For example, the finding that entry costs for large stores are higher in restrictive markets remains robust to the way we measure the stringency of regulation. Our empirical findings are robust to different definitions and cut-off points of the regulation index. Most importantly, the welfare results remain robust. ${ }^{4}$

\footnotetext{
${ }^{4}$ These results are available from authors upon request.
} 
Table H.1: Estimation results for structural parameters

\begin{tabular}{|c|c|c|c|c|}
\hline & \multicolumn{2}{|c|}{ Regulation measure 1} & \multicolumn{2}{|c|}{ 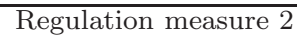 } \\
\hline & Small & Large & Small & Large \\
\hline Entry cost restrictive markets & $\begin{array}{r}9.263 \\
(4.249)\end{array}$ & $\begin{array}{r}111.781 \\
(38.903)\end{array}$ & $\begin{array}{r}20.946 \\
(6.050)\end{array}$ & $\begin{array}{r}144.294 \\
(34.487)\end{array}$ \\
\hline Entry cost liberal markets & $\begin{array}{c}10.665 \\
(2.749)\end{array}$ & $\begin{array}{r}105.834 \\
(24.699)\end{array}$ & $\begin{array}{r}8.819 \\
(2.027)\end{array}$ & $\begin{array}{r}96.177 \\
(24.522)\end{array}$ \\
\hline Fixed cost & $\begin{array}{r}1.041 \\
(0.590)\end{array}$ & $\begin{array}{r}4.590 \\
(1.074)\end{array}$ & $\begin{array}{r}0.100 \\
(0.518)\end{array}$ & $\begin{array}{r}5.680 \\
(1.399)\end{array}$ \\
\hline $\begin{array}{l}\text { NOTE: Regulation measure } 1 \\
\text { sented the main text; Regulati } \\
\text { level; Bootstrapped standard } \\
\text { defined as the five largest sto } \\
\text { large supermarkets, large groc } \\
\text { as having restrictive (liberal) } r \\
\text { is below (above) the median. } \\
\text { try costs for small and large st } \\
\text { with parameters } a_{1} \text { and } a_{2} \text {. }\end{array}$ & $\begin{array}{l}\text { ors are } \\
\text { types in } \\
\text { stores, } \\
\text { ulations } \\
\text { ed cost } \mathrm{f} \\
\text { s }\left(\kappa_{\text {smal }}\right.\end{array}$ & $\begin{array}{l}\text { f the reg } \\
\text { are of libe } \\
\text { ted in pe } \\
\text { I (hyper } \\
\text { aer stores } \\
\text { egulatior } \\
\text { an expol } \\
k_{\text {large }} \text { fo }\end{array}$ & $\begin{array}{l}\text { on index } \\
\text { eats at t } \\
\text { heses. L } \\
\text { ets, dep } \\
\text { unicipal } \\
\text { ex, defin } \\
\text { al distril } \\
\text { a unimo }\end{array}$ & $\begin{array}{l}\text { bles pre- } \\
\text { l market } \\
\text { tores are } \\
\text { tt stores, } \\
\text { e defined } \\
\text { ection 2, } \\
\text { The en- } \\
\text { tribution }\end{array}$ \\
\hline
\end{tabular}

\section{Appendix I: Ownership and entry and exit at the store level}

This section investigates whether it is reasonable to abstract from owners in our dynamic model. To do this we run simple reduced-form regressions for entry and exit probabilities at the store level. The results in Table I.1 show that the owner dummy variables are not statistically significant in simple linear probability regressions at the store level. Although this modeling approach has various disadvantages, it confirms that owners might not play an important role in our model setting. 
Table I.1: Estimation of linear probability models for exit and entry at the store level

\begin{tabular}{lrrrr}
\hline \hline & \multicolumn{2}{c}{ Exit } & \multicolumn{2}{c}{ Entry } \\
& Estimate & Std. & Estimate & Std. \\
\hline Dummy ICA & -0.0567 & 0.1380 & -0.1132 & 0.0855 \\
Dummy Axfood & -0.0243 & 0.1381 & -0.0911 & 0.0856 \\
Dummy Coop & -0.0479 & 0.1380 & -0.1113 & 0.0860 \\
Dummy Bergendahl & -0.0326 & 0.1382 & -0.0824 & 0.0857 \\
Dummy Other owners & 0.0000 & 0.1400 & -0.0855 & 0.0856 \\
& & & \multicolumn{2}{c}{ Yes } \\
Local market controls & Yes & \multicolumn{2}{c}{ Yes } \\
Year fixed effect & Yes & \multicolumn{2}{c}{ Yes } \\
Market fixed effect & Yes & \multicolumn{2}{c}{0.036} \\
$R^{2}$ & & \multicolumn{3}{c}{} \\
\hline
\end{tabular}

NOTE: No constant is included in the specification.

\section{References}

Pakes, A., M. Ostrovsky, and S. Berry (2007): "Simple Estimators for the Parameters of Discrete Dynamic Games (with Entry/Exit Examples)," The RAND Journal of Economics, 38(2), 373-399.

Swedish Competition Authority (2001:4): "Kan Kommunerna Pressa Matpriserna? (Can the Municipalities Put Pressure on Prices?)," Technical Report 4, Stockholm.

(2004:2): "Konsumenterna, Matpriserna och Konkurrensen (Consumers, Retail Food Prices, and Competition)," Technical Report 2, Stockholm. 